\title{
The effect of high strain rate deformation on intermetallic reaction during ultrasonic welding aluminium to magnesium
}

Dol:

10.1016/j.msea.2012.06.055

\author{
Document Version \\ Accepted author manuscript
}

Link to publication record in Manchester Research Explorer

Citation for published version (APA):

Panteli, A., Robson, JD., Brough, I., \& Prangnell, PB. (2012). The effect of high strain rate deformation on intermetallic reaction during ultrasonic welding aluminium to magnesium. Materials Science and Engineering A: Structural Materials: Properties, Microstructures and Processing , 556, 31-42. https://doi.org/10.1016/j.msea.2012.06.055

\section{Published in:}

Materials Science and Engineering A: Structural Materials: Properties, Microstructures and Processing

\section{Citing this paper}

Please note that where the full-text provided on Manchester Research Explorer is the Author Accepted Manuscript or Proof version this may differ from the final Published version. If citing, it is advised that you check and use the publisher's definitive version.

\section{General rights}

Copyright and moral rights for the publications made accessible in the Research Explorer are retained by the authors and/or other copyright owners and it is a condition of accessing publications that users recognise and abide by the legal requirements associated with these rights.

\section{Takedown policy}

If you believe that this document breaches copyright please refer to the University of Manchester's Takedown Procedures [http://man.ac.uk/04Y6Bo] or contact uml.scholarlycommunications@manchester.ac.uk providing relevant details, so we can investigate your claim.

\section{OPEN ACCESS}




\title{
The effect of High Strain Rate Deformation on Intermetallic Reaction during Ultrasonic Welding Aluminium to Magnesium
}

\author{
A. Panteli ${ }^{1 \mathrm{a}}$ J. D. Robson ${ }^{1}$ I. Brough $^{1}$ and P. B. Prangnell ${ }^{1 *}$. \\ ${ }^{1}$ Manchester Materials Science Centre, Grosvenor Street, Manchester, M1 7HS, UK. \\ alexandra.Panteli@postgrad.manchester.ac.uk, joseph.robson@manchester.ac.uk, \\ ian.brough@manchester.ac.uk, , philip.prangnell@manchester.ac.uk \\ *corresponding author
}

\begin{abstract}
High power ultrasonic spot welding (USW) is a low heat input solid-state joining process that may offer a solution for welding difficult dissimilar-material couples, like magnesium $(\mathrm{Mg})$ to aluminium ( $\mathrm{Al}$ ) for automotive body applications. However, the high strain rate dynamic deformation in USW has been claimed to accelerate inter-diffusion rates in dissimilar joints. The interfacial reaction between Al, AA6111, and Mg AZ31 alloys has been studied as a function of welding energy. For the optimum welding condition of $600 \mathrm{~J}(0.4 \mathrm{sec})$ the reaction layer thickness was already $\sim 5 \mu \mathrm{m}$ thick. Intermetallic reaction centres were found to nucleate within micro-welds at the interface at very short welding times and spread and grow rapidly to form a continuous layer, comprised of two sub-layers of $\mathrm{Al}_{12} \mathrm{Mg}_{17}$ and $\mathrm{Al}_{3} \mathrm{Mg}_{2}$. Interface liquation was also found for longer welding times at temperatures below the recognised lowest eutectic reaction temperature in the Al-Mg binary system. Modelling has been used to show that the solid state reaction kinetics were over twice the rate expected from parabolic growth predictions made using rate constants obtained under static test conditions. The reasons for this discrepancy and the depressed melting reaction are discussed.
\end{abstract}

Key Words: Intermetallic compounds; $\mathrm{Al}_{12} \mathrm{Mg}_{17} ; \mathrm{Al}_{3} \mathrm{Mg}_{2}$; reaction kinetics; ultrasonic welding 


\section{Introduction}

Aluminium (Al) and magnesium ( $\mathrm{Mg}$ ) are increasingly being substituted for steel in the automotive industry to reduce weight and increase fuel efficiency [1]. It is also becoming widely recognised that the future of automotive production will be based on a multi-materials approach, allowing more efficient use to be made of the best attributes of different classes of materials $[2,3,4]$. This will inevitably result in a greater need to join dissimilar combinations of metals, including aluminium and magnesium alloys. Unfortunately, fusion processes are very difficult to apply successfully to the welding of $\mathrm{Al}$ to $\mathrm{Mg}$ alloys because the welds are embrittled by the rapid formation of intermetallic compounds (IMC), owing to the high rates of diffusivity in the liquid phase [5,6]. As a result, solid state techniques like friction stir welding (FSW) and friction stir spot welding (FSSW) are attracting increasing interest for dissimilar joining applications (e.g. $[7,8,9]$ ). To date, it has been shown that defect-free Al to $\mathrm{Mg}$ welds can be achieved by FSW [9,10], but a significant level of intermetallic compound formation is still observed, which reduces the mechanical properties of the joints $[5,7,8,9,11]$. In FSW care must also be taken to control the temperature in order to avoid liquation caused by the low melting point eutectic reactions present in the Al-Mg system (see Fig. 1) [12].

The intermetallic compounds $\beta-\mathrm{Al}_{3} \mathrm{Mg}_{2}$ and $\gamma-\mathrm{Al}_{12} \mathrm{Mg}_{17}$ have been consistently reported to form in the nugget zone of $\mathrm{Al}$ to Mg FSWs [7,8,11,12]. These two phases have also been identified in a recent TEM study by Firouzdor and Kou [7]. To date, other possible intermetallic phases present in the Al-Mg system (e.g. R or $\varepsilon$, and $\lambda[13,14]$ ) have not been observed in welding. However, in FSW the reaction products are broken up into fine particles and redistributed by the severe deformation near the tool, making analysis of their growth behaviour and reaction kinetics difficult [15]. Studies of static diffusion couples between $\mathrm{Al}$ and $\mathrm{Mg}$ have shown that, when undeformed, the IMC reaction layer typically develops with two continuous sub-layers: $\mathrm{Mg}_{17} \mathrm{Al}_{12}$ on the $\mathrm{Mg}$ side and $\mathrm{Al}_{3} \mathrm{Mg}_{2}$ on the $\mathrm{Al}$ side of the interface $[16,17,18]$. The growth kinetics of the overall IMC layer and sub-layers follows the expected parabolic behaviour. However, important in the context of dissimilar welding, the growth rate is abnormally rapid due to the high rate of diffusion through the reaction layer and, in particular, in the $\beta-\mathrm{Al}_{3} \mathrm{Mg}_{2}$ phase, which results in a low growth activation energy $[17,19]$.

Ultrasonic Spot Welding (USW) is an alternative solid state joining technique to FSSW that can produce welds with a lower energy input [20] and is therefore of interest for joining reactive dissimilar metals, like aluminium and magnesium. Although USW has been used since the 1950s to successfully join thin foils with various dissimilar material combinations [21], higher power welding systems have only been applied to thicker (1 $-2 \mathrm{~mm})$ automotive sheet relatively recently (e.g. [20,22,23]). Research on lower power USW shows that bonding occurs at moderate temperatures $\left(<300^{\circ} \mathrm{C}\right)$ and is dominated by contact mechanics, with any deformation localised to the weld faying surfaces [21,23,24]. Weld formation initially involves ultrasonic vibration breaking down the surface oxide layer between contacting asperities, resulting in local adhesion and the formation of microwelds [20,22]. It has been found that when welding thicker $(\sim 1 \mathrm{~mm})$ automotive sheet, with higher power systems, optimum weld properties are only obtained when the microbonds fully coalesce across the weld interface. In similar-material $\mathrm{Al}$ welds this has been observed to require plastic deformation to propagate throughout the entire sheet thickness between the sonotrode tips and in comparison involves considerably greater welding energies [22]. For example, welding energies of the order of $700 \mathrm{~J}$ are required to produce optimised welds in $1 \mathrm{~mm}$ thick $\mathrm{Al}$ sheet that exhibit the desired nugget pull-out failure behaviour [20,22]. Because of the higher energy input, when ultrasonic spot welding $1 \mathrm{~mm}$ thick sheet, Chen et al. have measured peak temperatures at the interface in $\mathrm{Al}$ welds to be above $400{ }^{\circ} \mathrm{C}$ [23]. 
As well as the more substantial temperature rise seen in high power USW of Al sheet, an important consideration in dissimilar joining is the high strain rate $\left(\varepsilon^{*} \sim 10^{3} \mathrm{~s}^{-1}[25]\right)$ dynamic deformation caused by the USW process. It has been claimed that this can result in accelerated reaction kinetics. For example, in their study of $\mathrm{Zn}$ to $\mathrm{Al}$ dissimilar joints, Gundaz et al. [25] have reported both enhanced inter-diffusion rates and a significantly depressed melting point, which they attributed to the presence of the large concentration of deformationinduced vacancies generated by USW. Chen et al. have also noted an effect of deformation induced vacancies on post-weld natural ageing in Al USWs [23]. Potentially, such effects could have an important influence on the intermetallic reaction kinetics when ultrasonic welding $\mathrm{Al}$ to $\mathrm{Mg}$.

Currently, little work has been published on the role of deformation on the intermetallic reaction behaviour seen when ultrasonic welding $\mathrm{Al}$ to $\mathrm{Mg}$, especially with the higher power systems required for thicker gauge automotive sheet. Previous work by Panteli et al. has sought to optimise the welding parameters for $\mathrm{Al}$ to $\mathrm{Mg}$ using the USW technique. This work showed that pre-grinding the surfaces of the weld coupons and increasing the clamping force (up to $1.9 \mathrm{kN}$ ) improved strength. However, even under optimised conditions, they could not produce welds of sufficient strength to fail by nugget pull-out and this was attributed to the rapid formation of a brittle intermetallic layer at the joint interface [26].

Here, we have investigated in detail how the intermetallic reaction layer forms and influences the joint performance when performing dissimilar ultrasonic spot welds between the aluminium and magnesium automotive alloys AA6111 and AZ31, in $1 \mathrm{~mm}$ thick gauge sheet. The evolution of the IMC reaction layer and growth rate has been studied as a function of welding time/energy and related to accurate measurements of the interface temperature. To determine the effect of the high strain rate dynamic deformation inherent to the USW process, the reaction layer thickness has been compared to predictions of the growth rate under static conditions, as well as to thermodynamic calculations of the melting point at the joint interface. It is also worth noting that the conclusions of this analysis are applicable to other joining process involving intense deformation, such as in FSW, where the interface behaviour is more difficult to interpret owing to the more extensive material flow that can occur in the weld zone.

\section{Experimental}

The welds investigated were produced between aluminium AA6111-T4 and magnesium AZ31-H24 alloy, $1 \mathrm{~mm}$ thick sheets. The hot rolled Mg sheet was first prepared by grinding off the thick oxide using 320 grit $\mathrm{SiC}$ paper, whereas the cleaner $\mathrm{Al}$ sheet was welded in the as-rolled condition. Both materials were thoroughly degreased with ethanol prior to welding. Ultrasonic spot welding was performed with a Sonobond dual-head spot welder operating at a frequency of $20.5 \mathrm{kHz}$ and a nominal power of $2.5 \mathrm{~kW}$ (machine setting). The materials were welded between two $9 \mathrm{~mm} \times 6 \mathrm{~mm}$ sonotrode tips, which had nine parallel ridged teeth orientated perpendicular to the direction of vibration (see ref [22] for full details). Laser vibrometry was used to measure the amplitude of oscillation at the sontrode tip, which was 5-6 $\mu \mathrm{m}$. Welding was performed with a constant power setting, $\mathrm{P}$, for increasing welding times, $t$, and weld energy, $\mathrm{U}$, (where $\mathrm{U} \sim$ P.t) using a clamping force of $1.9 \mathrm{kN}$. The actual power delivered to the weld members varied in the range 1200 to $1500 \mathrm{~W}$ depending on the coupling between the sheers and welding tips. The welds were made at the centre of a $25 \mathrm{~mm}$ overlap on $100 \times 25 \mathrm{~mm}$ coupons held with light manual clamping. The weld temperatures were measured as close as possible to the join line at the weld centre, the hottest location in the weld [23], using embedded sacrificial $0.5 \mathrm{~mm}$ K-type thermocouples. The thermocouples were inserted through a groove in the top aluminium sheet. Temperature measurements were 
repeated several times and only the results that gave 'reliable' heating and cooling curves were retained (i.e. time-temperature histories with a similar profile to that expected from modelling with no inflections). DSC analysis was also performed on pre-welded samples, using a heating rate of $10 \mathrm{~K} \mathrm{~s}^{-1}$, to measure the incipient melting point at the interface under static conditions.

Tensile lap shear testing was carried out on the welded samples using a cross-head speed of $0.5 \mathrm{~mm} \mathrm{~min}{ }^{-1}$, with both the peak load and fracture energy (area under the load-displacement curve) measured. Metallographic samples were prepared from the weld cross sections using standard procedures, with oil-based lubricants, and finished using a water-free colloidal silica suspension. Microhardness tests were carried out on flat, polished samples using a Vickers CSM micro-indentation hardness testing. Imaging was carried out by conventional optical microscopy and with a Philips XL30 or FEI Sirion FEG SEM. Phase identification of the reaction layer was performed by high resolution EBSD with a step size of $0.01 \mu \mathrm{m}$ on samples prepared by removing the surface layer across the weld interface with an FEI Quanta 3D dual beam FIB, to obtain a strain free surface.

\section{Modelling}

Modelling was utilised to help clarify if there was a significant effect of the dynamic deformation during USW on; i) the reaction rate and ii) the eutectic melting point at the weld interface. Both of these phenomena have been previously reported by Gundaz et al. and attributed to the high strain rate dynamic conditions present in ultrasonic welding [25].

The intermetallic growth kinetics were measured in static isothermal heat treatments using lightly pre-welded samples (300J / $0.24 \mathrm{~s}$ ) placed in a pre-heated furnace, at temperatures in the range of $330-400^{\circ} \mathrm{C}$, for up to 200 hours. The growth rate constants and activation energy could then be determined from the average intermetallic layer thickness, using the following standard expressions for one dimensional diffusion controlled parabolic growth [27]:

$$
\mathrm{x}^{2}=\mathrm{kt}
$$

where $\mathrm{x}$ is the layer thickness, $\mathrm{t}$ is the heating time, and $\mathrm{k}$ is the growth rate constant. The temperature dependence of $\mathrm{k}$ is expressed by the Arrhenius equation;

$$
\mathrm{k}=\mathrm{k}_{0} \exp \left(-\frac{\mathrm{Q}}{\mathrm{RT}}\right)
$$

where $\mathrm{k}_{0}$ is the pre-exponential factor, $\mathrm{Q}$ is the activation energy, $\mathrm{R}$ is Boltzmann's constant and $\mathrm{T}$ is absolute temperature. The activation energy was calculated from a $\ln (\mathrm{k})$ vs. 1/T plot, where the slope is equal to - $\mathrm{Q} / 2 \mathrm{R}$. These results were validated against published data $[16,17]$. Thermal cycles measured from real welds were then used to predict the expected reaction layer thickness, by integration across small discreet time steps, using the rate constants obtained under static conditions (i.e. excluding any effects of dynamic deformation) from:

$$
\mathrm{dx}=\frac{\mathrm{k}}{\mathrm{x}} \mathrm{dt}
$$

The influence of alloying additions present in the AA6111 and AZ31 sheets, on the melting point expected for the lowest temperature $(\mathrm{Mg})_{\mathrm{SS}}+\gamma-\mathrm{Mg}_{17} \mathrm{Al}_{12} \rightarrow \mathrm{L}$, eutectic reaction present in the binary Al-Mg system, was also been explored using the proprietary Calphad code JMatPro $^{\mathrm{TM}}$. This was carried out in order to help verify if the high vacancy flux generated by 
ultrasonic deformation could affect the onset temperature of melting reactions at the weld interface, as has been previously claimed by Gundaz et al. [25].

\section{Results}

\subsection{Joint Performance}

Fig. 2 summarises the lap shear test results obtained from the dissimilar Al-Mg welds, as a function of welding energy, compared to results for similar $\mathrm{Al}-\mathrm{Al}$ and $\mathrm{Mg}-\mathrm{Mg}$ welds performed between the same two AA6111 and AZ31 alloy sheets under identical conditions. Examples of the joint fracture surfaces are also given in Fig. 3. For the Al-Al and $\mathrm{Mg}-\mathrm{Mg}$ welds, the shear strength increased with welding energy until maximum strengths of $3.4 \mathrm{kN}$ and $2 \mathrm{kN}$ were reached, respectively, and then gradually decreased with higher energy inputs. It can be seen that the failure energies for the Al-Al similar welds follow a step function with welding energy, and a transition occurs at about $500 \mathrm{~J}$. Above this welding energy the failure energy rapidly increased because it took place by the more energy-intensive nugget pull-out mode (Fig. 3); whereas for too low welding energies, where the microbond density was too low failure occurred by interface failure [22]. For the Mg alloy, the optimum weld strength was about half that of the Al-Al welds, but the curves showed a similar overall form. Nugget pullout was again observed in the higher energy plateau region in the failure energy curve (Fig. 3b), although the maximum failure energy was around half that of the Al-Al welds.

The dissimilar Al-Mg welds showed a similar initial rise in lap shear strength with increasing weld energy and reached a maximum of $2.0 \mathrm{kN}$ after a welding time of $0.4 \mathrm{~s}(600 \mathrm{~J})$ which was equivalent to the optimum strength of the $\mathrm{Mg}-\mathrm{Mg}$ similar welds. However, the dissimilar combination exhibited a much more rapid decrease in strength at higher welding energies, or longer welding times. Furthermore, with the Al-Mg welds, failure always occurred at the interface and there was no transition to a pull-out mode at higher welding energies. As a result, the maximum failure energy only reached $1.2 \mathrm{kN} . \mathrm{mm}$, which was less than half that required to fracture an optimised $\mathrm{Mg}-\mathrm{Mg}$ weld (which did exhibit nugget pullout).

In Fig. 4 weld cross sections are shown from dissimilar Al-Mg USWs produced with optimum $(0.4 \mathrm{sec})$ and long $(1.0 \mathrm{sec})$ weld times. Sound welds are seen in each case with little evidence of a lack of bonding. However, even by optical microscopy, a thick interfacial reaction layer can already be seen to develop in the samples after a $0.4 \mathrm{sec}$ welding time.

\subsection{Weld Interface Temperatures}

To measure the maximum temperature reached in the ultrasonic welds, a thin $(0.5 \mathrm{~mm})$ thermocouple was positioned at the centre of the weld area through a grove machined in the Al sheet, in contact with the top and bottom sheets. As some thermocouples were damaged during the weld cycle, and it was difficult to ensure that the tip stayed perfectly in the correct location, the tests were repeated many times. The peak temperatures measured for different weld energies in these tests are shown in Fig. 5. The highest average peak temperatures recorded, that were consistently re-produced to $\pm 2{ }^{\circ} \mathrm{C}$ in three repeated welds, are shown as solid points (examples of measured thermo-cycles can be found below in Fig 14a). The maximum peak temperatures measured at the join line (solid trend line in Fig. 5) were higher than previously reported for similar metal welds for the same welding energy (e.g. $[22,23,28]$ ) and exceeded $400{ }^{\circ} \mathrm{C}$, even for the optimum welding energy $(600 \mathrm{~J})$. For higher welding energies the maximum temperature increased at a diminishing rate and reached a maximum of $432 \pm 2{ }^{\circ} \mathrm{C}$ after a 1.3 second welding time. 


\subsection{Interface Reaction}

Fig. 6 illustrates how the IMC reaction layer developed with increasing weld duration (or energy) at the centre of the sonotrode tip contact area. At short weld times (Fig. 6a) the reaction layer thickness was not uniform and isolated reaction centres (or IMC 'islands') were observed. The IMC islands thickened by growing mainly outwards into the $\mathrm{Mg}$ side of the weld, but spread laterally more rapidly until they coalesced to form a continuous layer across the weld interface after a welding time of $\sim 0.25$ seconds. At this stage the IMC reaction layer was already approximately $3 \mu \mathrm{m}$ in thickness. With longer welding durations the layer continued to increase uniformly in thickness (Fig 6 b-d). After a one second welding time the IMC layer was $20 \mu \mathrm{m}$ thick and two distinct sub-layers could be seen in the SEM images. However, further analysis revealed that the two sub-layers were already present in the optimum 0.4 second weld (see Fig. 7b). Defects were also observed within the IMC layer, which were probably partly artefacts caused by grains falling out of the surface during sample preparation (e.g. Fig. 6c). When the weld energy reached greater than $1500 \mathrm{~J}(1.3 \mathrm{sec})$ evidence of melting could be observed on the magnesium side of the joint interface. In Fig. 6e it can be seen that, at the highest weld energy investigated, the IMC sub-layer adjacent to the magnesium side of the weld had completely melted and re-solidified with a dendritic structure containing a high volume fraction of eutectic.

More detailed analysis was performed using EBSD in the SEM to discriminate between the different phases present. The results of EBSD pattern quality contrast and phase mapping are presented in Fig. 7. The presence of both the $\beta-\mathrm{Al}_{3} \mathrm{Mg}_{2}$ and $\gamma-\mathrm{Al}_{12} \mathrm{Mg}_{17}$ phases was first confirmed by x-ray diffraction performed on both halves of fractured weld samples (Fig. 8) and EDS analysis of the thicker layers gave stoichiometries consistent with these compounds (Fig. 9). Although the occurrence of low volume fractions of other IMCs cannot be completely ruled out, no other phases were detected in the current study. For phase mapping, the crystal systems and lattice parameters for the $\beta-\mathrm{Al}_{3} \mathrm{Mg}_{2}$ and $\gamma-\mathrm{Al}_{12} \mathrm{Mg}_{17}$ phases obtained from the literature $[18,29,30]$ were used to index the EBSD Kikuchi patterns. It should be noted that high levels of indexing of the thin IMC layers was very difficult and reached only 40-60\%, owing to their thin nature, fine internal structure, and difficulties with sample preparation. In addition, the $\beta-\mathrm{Al}_{3} \mathrm{Mg}_{2}$ phase has a very complex and large unit cell containing 1,168 atoms [29,31,32], which can make correct crystallographic indexing by the EBSD technique unreliable [18]. In contrast to the work of Dietrich et al. [18] this phase proved easier to index than the $\gamma-\mathrm{Al}_{12} \mathrm{Mg}_{17}$ phase, which is probably due to the different (FIB) sample preparation techniques used in this study which gave better pattern quality for this phase.

The EBSD phase maps in Fig. 7 have been 'cleaned' for clarity, but should be treated with some caution, especially with regard to the absolute grain size. Taken together, the data in Figs. $6-9$ is sufficient to conclude the following. In the initial stages the IMC islands that form first are the $\gamma-\mathrm{Al}_{12} \mathrm{Mg}_{17}$ phase. This compound nucleates on the aluminium surface and grows predominantly into the magnesium side of the weld, as well as rapidly spreading sideways, to form a continuous layer of $\gamma-\mathrm{Al}_{12} \mathrm{Mg}_{17}$ (Fig. 7a). Once the continuous layer was complete, a second intermetallic layer of $\beta-\mathrm{Al}_{3} \mathrm{Mg}_{2}$ developed below the $\mathrm{Al}_{12} \mathrm{Mg}_{17}$ layer on the aluminium side of the interface (Fig. 7b). Although the entire IMC layer continued to grow with a fairly uniform total thickness, the $\beta$ phase developed at a much higher rate, becoming the thicker of the two sub-layers after a welding time of $0.9 \mathrm{~s}$ (Fig. 7d).

As noted above, at longer welding times (past optimum) the $\gamma-\mathrm{Al}_{12} \mathrm{Mg}_{17}$ sub-layer on the magnesium side started to melt (Fig. $6 \mathrm{~d}$-e). This presumably occurs through the $(\mathrm{Mg})_{\mathrm{Ss}}+\gamma-$ $\mathrm{Mg}_{17} \mathrm{Al}_{12} \rightarrow \mathrm{L}$ eutectic, which has the lowest reaction temperature in the Al-Mg binary system $\left(437^{\circ} \mathrm{C}\right)$. However, there was also some evidence of melting occurring at the $\beta-\gamma$ 
interface (Fig. 6d). Melting did not initiate uniformly across the interface, which suggests hotspots may have been present as a result of local variations in the rate of energy dissipation from the ultrasonic vibration, but was first noted to occur when the maximum interface temperature (measured in the repeated tests) reached $422 \pm 2{ }^{\circ} \mathrm{C}$ (Fig. 6d welding energy 1300 J). Full melting of the $\mathrm{Al}_{12} \mathrm{Mg}_{17}$ layer took place at $432{ }^{\circ} \mathrm{C}$ (Fig. 6e welding energy $1500 \mathrm{~J}$ ).

The EBSD maps in Fig. 7 show that the grain structures of the $\gamma-\mathrm{Al}_{12} \mathrm{Mg}_{17}$ and $\beta-\mathrm{Al}_{3} \mathrm{Mg}_{2}$ sublayers coarsened with increasing welding time, although this effect was more significant in the case of the $\gamma$ phase. The average grain sizes were of the order of $1 \mu \mathrm{m}$ and $2 \mu \mathrm{m}$ in the $\gamma$ $\mathrm{Al}_{12} \mathrm{Mg}_{17}$ and $\mathrm{Al}_{3} \mathrm{Mg}_{2}$ layers, respectively, in the sample welded with a 0.5 second duration and increased to $3 \mu \mathrm{m}$ and $4 \mu \mathrm{m}$ in the 0.9 second weld. The two sub-layers also showed some indication of a columnar structure, (e.g. Fig. 7b) which was more obvious in the $\gamma-\mathrm{Al}_{12} \mathrm{Mg}_{17}$ phase. An attempt was made to perform texture analysis on the EBSD data. Pole figures are shown in Fig. 10 only from the $\beta-\mathrm{Al}_{3} \mathrm{Mg}_{2}$ phase, as the level of indexing of the $\gamma-\mathrm{Al}_{12} \mathrm{Mg}_{17}$ sub-layer was too low. The data suggests the possibility of a weak $\langle 111\rangle$ fibre texture.

Finally, in Fig. 11 a micro-hardness profile is shown across half a weld interface cross-section, for the $0.9 \mathrm{~s}$ weld, where the IMC layer was thick enough for the hardness to be reliably measured. It can be seen that the intermetallic layer is significantly harder than the parent materials, and exhibited a hardness level nearly four times that of the AZ31 magnesium alloy [18].

\subsection{Isothermal Treatments}

Isothermal treatments were performed on lightly pre-welded samples at two temperatures of 380 and $400{ }^{\circ} \mathrm{C}$ (i.e. below the melting point) in order to validate static growth kinetic data published Tanguep Njiokep et al. [17] for the IMC reaction layer, in the lower temperature and shorter time regime more relevant to USW. In Fig. 12 the kinetic data obtained from these experiments, in the range from where a continuous layer had first formed, is summarised and compared to the work of Tanguep Njiokep et al. [17] for longer term heat treatments. It can be seen that the new data measured here fits well with the published results. In the logarithmic plot of thickness against time (Fig. 12a) the gradients of both sets of data are approximately 0.5, which is expected for parabolic diffusion controlled growth. The more limited data for thickness against temperature also fits closely with the results reported from Tanguep Njiokep et al.'s diffusion bonding experiments, confirming that the activation energies they proposed for the growth rates of the $\gamma-\mathrm{Al}_{12} \mathrm{Mg}_{17}$ and $\beta-\mathrm{Al}_{3} \mathrm{Mg}_{2}$ sub-layers are reliable.

\subsection{Modelling}

\section{Growth kinetics}

The parabolic kinetic growth law was used to investigate if there was any evidence of a systematic change in the growth kinetics of the IMC layer under the high strain rate dynamic conditions present in USW. As the static data obtained here fitted very well with the work published by Njiokep et al [17], the two sets of results were combined to calculate the activation energy and pre-exponential factor, $\mathrm{k}_{0}$, for the growth rate of the entire layer. Linear regression fitting gave an activation energy of $65 \mathrm{~kJ} \mathrm{~mol}^{-1}$ and value of $\mathrm{k}_{0}=5 \times 10^{4} \mu \mathrm{m}^{2} \mathrm{~s}^{-1}$ for the entire layer thickening rate, which is in reasonable agreement with the low activation energy for diffusion of $\mathrm{Al}$ through the more rapidly growing $\mathrm{Al}_{3} \mathrm{Mg}_{2}$ sub-layer determined by Tanguep Njiokep et al. of $69 \mathrm{~kJ} \mathrm{~mol}^{-1}$ [17] (shown in Table 1).

With these fitted rate constants, equation 3 was used to the predict the overall IMC layer thickness for two heat treatment temperatures of $380^{\circ} \mathrm{C}$ and $400^{\circ} \mathrm{C}$, which are close to the 
peak temperatures measured in the USWs. The calculated curves are compared to the experimental data in Fig. 13b and give good agreement (solid lines). This fitted growth law was then applied to the measured weld thermal cycles shown in Fig. 14a, to predict the intermetallic layer growth during welding, without taking into account the effect of deformation.

Fig. 14b shows that the predicted growth rate is very sensitive to temperature and increases dramatically as the welding energy rises, with a negligible increase in thickness occurring during cooling, once the peak weld temperature has been reached. In Fig. 14c the predicted final layer thickness after welding is compared to the thicknesses measured in the actual samples from which the interface temperature cycle was measured. The layer thickness can be seen to increase exponentially with peak weld temperature/ weld energy, but reaches a limit in the real data when melting starts to occur at high welding energies. Overall, the predicted layer width can be seen to be much lower than that of the actual layer and is about $60 \%$ below the measured thickness. While every effort was made to obtain reliable temperature measurements (see above), due to the rapid nature of the welding cycle, a systematic error cannot be ruled out. In particular, thermal lag or incorrect thermocouple positioning is always a distinct possibility. Predictions were therefore also made with an assumed error of $5 \%$ and $10 \%$ in the temperature measurements by scaling the recorded thermal. In, for example, the $1000 \mathrm{~J}$ weld a $5 \%$ increase corresponds to an increase in peak temperature of $\sim 20{ }^{\circ} \mathrm{C}$. As will be seen below, where the DSC results are discussed, this error is greater than that measured by comparison of thermal analysis of the melting point reaction onset temperature with thermal couple measurements which gave a difference of $\sim 10{ }^{\circ} \mathrm{C}$. Even allowing for this potential error in the thermal measurements, the predicted reaction layer width was still about $50 \%$ of the measured thickness. Hence, it appears that the dynamic growth rates were greater than those predicted, using static parabolic growth data, by at least a factor of two.

\section{Interface melting}

At higher weld energies melting was observed at the interface between the $\mathrm{Al}_{12} \mathrm{Mg}_{17} \mathrm{IMC}$ layer and the magnesium alloy substrate, through the $(\mathrm{Mg})_{\mathrm{SS}}+\gamma-\mathrm{Mg}_{17} \mathrm{Al}_{12} \rightarrow \mathrm{L}$ eutectic reaction, but this occurred at a lower temperature than expected from the Al-Mg binary phase diagram. Because of this observation, and the possibility that intense high strain-rate ultrasonic deformation can potentially depress the melting point [25], Calphad modelling [33] was used to predict the incipient melting range of the AZ31 and AA6111 couple. Using an overall composition of $64.89 \mathrm{Mg}-33.41 \mathrm{Al}-0.68 \mathrm{Zn}-0.44 \mathrm{Mn}-0.27 \mathrm{Si}-0.23 \mathrm{Cu}-0.08 \mathrm{Fe}$ wt.\%, which was based on a ratio of each alloy equivalent to the ideal binary eutectic composition for this reaction (i.e. $67.7 \mathrm{wt} . \% \mathrm{Mg}-32.3 \mathrm{wt} . \% \mathrm{Al}$ ), the predicted solidification behaviour of the alloy couple was compared to that expected for the binary Al-Mg system. From Fig. 15a it can be noted that when additional minor alloy elements are present the liquid does not terminate abruptly at the eutectic temperature, rather there is predicted to be a more gradual freezing response of the solute enriched remaining eutectic liquid, which depresses the melting point significantly below $437^{\circ} \mathrm{C}$. Calphad simulation with and without the additional alloy elements present in the commercial materials showed that this melting point shift can be attributed largely to the presence of $\mathrm{Cu}$ and $\mathrm{Si}$ in the 6111 alloy sheet (Fig. 15a).

In addition, DSC analysis was performed on samples welded with an energy of $900 \mathrm{~J}$ which was sufficient to produce a thick reaction layer, but below the threshold where melting was observed. Results from this analysis are shown in Fig. 15b and indicate that, when measured in the DSC under static conditions, melting first occurs at $432{ }^{\circ} \mathrm{C}$, which is slightly below the binary Al-Mg eutetcic melting point and only about $10^{\circ}$ higher than the interface temperature measurements in the weld sample where melting was first observed. The DSC measurements 
thus give further confidence in the reliably of the thermocouple data used to predict the interface reaction layer thicknesses described above.

\section{Discussion}

In ultrasonic metal welding of similar materials, the accepted mechanism for weld formation involves the formation and progressive spreading of microwelds [22,24]. As the welding time increases, and the net welded area expands, the weld strength consequently initially increases until failure occurs by the nugget pull-out mode (Fig. 2) [20,22]. In this case, the subsequent decrease in weld strength seen for longer weld times is related to the increasing penetration of the sonotrode tips into the sheet surfaces (e.g. Fig. 4) which causes thinning of the weld area $[20,22]$. When considering the dissimilar Al-Mg welds, the initial trend for increasing lapshear strength with welding energy followed that of the weaker $\mathrm{Mg}-\mathrm{Mg}$ similar welds (Fig. 2a). Encouragingly, for the optimum weld time $(0.4 \mathrm{sec})$ the dissimilar joint strength reached the same as that for the $\mathrm{Mg}-\mathrm{Mg}$ weld. However, at longer welding times (higher welding energies) the decrease in strength of the Al-Mg joints was much more rapid than can be explained by sheet thinning. Furthermore, the fracture energy for the Al-Mg joints was less than half that of the Mg-Mg similar welds (Fig. 2b) and failure always occurred at the joint interface (Fig. 3).

The rapid formation of brittle intermetallic phases has been widely cited as a major problem in welding aluminium to magnesium $[5,7,8,9,11]$ and here was equally responsible for the inferior mechanical properties found for the Al-Mg welds, which had low fracture energies and deteriorated more quickly than the similar welds with welding time as the IMC layer increased in thickness. It can be seen from Figs. 2a and 6 that the welding time at which the Al-Mg strength curve began to deviate from the Mg-Mg curve corresponds 0.4 seconds $(600 \mathrm{~J})$ at which point the IMC layer was already continuous and had grown to a thickness of $\sim 5 \mu \mathrm{m}$. This rapidly increasing thickness of the brittle IMC layer readily accounts for the higher rate of deterioration of the Al-Mg joint's mechanical properties, relative to the $\mathrm{Mg}-\mathrm{Mg}$ or $\mathrm{Al}-\mathrm{Al}$ welds, with higher welding energies. Thus, understanding the growth kinetics and nature of the IMC reaction layer is critical to predicting the joint properties in dissimilar Al-Mg USWs.

\section{IMC Layer Growth Behaviour}

It is possible to form a range of intermetallic phases in the Al-Mg binary system $[13,14,30]$ as well as the $\gamma-\mathrm{Al}_{12} \mathrm{Mg}_{17}$ and $\beta-\mathrm{Al}_{3} \mathrm{Mg}_{2}$ phases observed above $[5,7,8,9,11]$. However, the phase diagram is still uncertain in the range $35-55$ at. $\% \mathrm{Mg}$, where the existence of the $\mathrm{R}$ [14], or $\varepsilon$ phase [13] (composition of 56.6 at $\% \mathrm{Al}$ ), plus an additional $\lambda$ phase has been claimed [13]. In addition, the $\beta$ phase can transform to a lower temperature $\beta$ ' rhombohedra form below $240{ }^{\circ} \mathrm{C}$ [31]. To date, only the $\gamma-\mathrm{Al}_{12} \mathrm{Mg}_{17}$ and $\beta-\mathrm{Al}_{3} \mathrm{Mg}_{2}$ phases have been positively identified in the interface region in friction welded, or diffusion bonded, Al-Mg samples, with the $\mathrm{R}$ phase only occasionally mentioned after exposure to extended heat treatments $[7,11,12,16-18,34]$. In the work presented here, the $\gamma$ and $\beta$ phases were again the only IMC phases detectable in significant volume fractions. This is probably because the other phases are known to have sluggish kinetics and, or, only exist at too low temperatures $[13,31]$. The $\gamma$ and $\beta$ compounds are extremely brittle [5] and readily account for the poor properties of Al$\mathrm{Mg}$ welds when present as a continuous layer of sufficient thickness at the joint interface.

In the ultrasonic welds, at very short weld times $(<0.25 \mathrm{sec})$, the intermetallic reaction layer was observed to first form in islands at the weld interface (Fig. 6a). The mechanism of formation of these isolated reaction centres appears to be related to the development of microwelds. In USW, metal-metal contact first occurs at abrading asperities across the 
interface plane, where the oxide layer breaks down due to the ultrasonic vibration, high pressure, and heat generation [24]. As the temperature rises, inter-diffusion becomes significant in the microweld regions and this leads to the nucleation of intermetallic compounds within these first locally welded points. The first intermetallic compound observed was the $\mathrm{Al}_{12} \mathrm{Mg}_{17}$ phase which formed on the $\mathrm{Al}$ side of the weld interface. The phase that nucleates earliest is expected to be the one that contains the highest proportion of the fastest diffusing species in either of the two matrices ( $\mathrm{Al}$ or $\mathrm{Mg}$ ) [35], and $\mathrm{Mg}$ in $\mathrm{Al}$ has a lower activation energy for diffusion than $\mathrm{Al}$ in $\mathrm{Mg}[6,36]$. The $\mathrm{Al}_{12} \mathrm{Mg}_{17}$ phase thus nucleates first because the $\mathrm{Al}$ matrix will become saturated with $\mathrm{Mg}$ solute earlier and, assuming there is no great difference in the energy barrier to nucleation, this leads to nucleation when a sufficient driving force (supersaturation) has been achieved [35].

Once formed, the $\mathrm{Al}_{12} \mathrm{Mg}_{17}$ islands grew predominantly into the $\mathrm{Mg}$ side of the weld (Fig. 6a) and spread sideways along the interface until a continuous layer developed. The transition from the initial observation of $\mathrm{Al}_{12} \mathrm{Mg}_{17}$ islands to their impingement and the development of a continuous layer occurred very early in the welding process, after a welding time of less than $\sim 0.25$ seconds. As in this initial stage the intermetallic layer was non-continuous, both the $\mathrm{Al}$ and $\mathrm{Mg}$ species were readily available between the IMC islands and diffusion could then occur rapidly along the interface between the IMC and the matrix. However, once the layer became continuous, diffusion would have to take place through the intermetallic layer, which acts as a barrier to diffusion. Indeed, it has been predicted that the interface controlled growth rate is approximately two orders of magnitude greater than growth by diffusion through the IMC layer, and this leads to rapid spreading of the IMC islands [37].

The static growth experiments showed that the growth rate of the continuous layer follows the expected one-dimensional diffusion controlled parabolic growth law (Fig. 12a). However, with longer weld times, a second IMC sub-layer of the $\beta-\mathrm{Al}_{3} \mathrm{Mg}_{2}$ phase developed on the aluminium side of the interface. This phase formed once diffusion through the thickening $\gamma$ $\mathrm{Al}_{12} \mathrm{Mg}_{17}$ phase slowed down sufficiently for it to become depleted in $\mathrm{Mg}$ near the aluminium substrate interface. Once formed, the $\beta-\mathrm{Al}_{3} \mathrm{Mg}_{2}$ sub-layer thickened at a faster rate than the pre-existing $\mathrm{Al}_{12} \mathrm{Mg}_{17}$ layer and became dominant after a welding time of one second.

Measurements of the thickening rate of the individual phases performed in static tests, under isothermal conditions with lightly pre-welded samples, showed remarkably good agreement with the kinetic fitting parameters published by Tanguep Njiokep et al. [17], given in Table 1 (Fig. 12). This data suggests an abnormally low activation energy, of only $\sim 65 \mathrm{~kJ} \mathrm{~mol}^{-1}$, is responsible for the higher growth rate of the $\beta-\mathrm{Al}_{3} \mathrm{Mg}_{2}$ phase. This low activation energy may be a consequence of the unusual polytetrahedral 'giant' crystal structure of the $\beta$, or 'Sampson' phase, which does not exhibit full occupancy of all its available lattice sites [30,32]. Another possibility is that diffusion though the $\beta-\mathrm{Al}_{3} \mathrm{Mg}_{2}$ phase sub-layer is dominated by grain boundary diffusion, although the grain size observed was similar to that of the slower growing $\gamma$ phase.

Significant coarsening of the grain structure in both sub-layers was also noted with increasing welding time. However, while slightly columnar in morphology the finer USW IMC layer grain structures were not as directional as those observed in long term diffusion bonding experiments. For example, in work by Dietrich et al. [18], on samples heat treated for up to two hours at $430{ }^{\circ} \mathrm{C}$, a far larger grain size was observed which spanned the layer thickness, leading to a 2-dimensional grain boundary structure similar to that typically seen in thin films. In the case of $\gamma-\mathrm{Al}_{12} \mathrm{Mg}_{17}$ phase, these much thicker layers $(\sim 40 \mu \mathrm{m})$ grown under static conditions were reported to have a stronger crystallographic texture, which was also been found to consist of a $<111>$ fibre texture [18]. 


\section{Dynamic vs Static Growth Kinetics}

It has been suggested by Gundaz et al. [25] that high strain rate $\left(\varepsilon^{\bullet} \sim 10^{3} \mathrm{~s}^{-1}\right)$ intense dynamic deformation in USW can produce a large excess concentration of deformation induced vacancies and that this can accelerate inter-diffusion across the interface between dissimilar metal couples. More recently, it has been demonstrated that the excess vacancy population predicted in USW is very dependent on their annihilation rate, which is strongly affected by the sink density and temperature [23]. This same work has also shown that accelerated natural ageing can be detected in aluminium ultrasonic welds and gives evidence of retained postweld deformation-induced vacancy concentrations at least 100 times greater than in conventionally solution treated and quenched samples [23]. Comparison of the reaction layer thickness in welds with model predictions using the static kinetic rate constants from Tanguep Njiokep et al. [17] and those measured here (Fig. 13), suggests that the influence of enhanced matrix diffusivity is not as high as proposed by Gundaz et al [25], when a continuous layer has developed. Gundaz et al. [25] claim inter-diffusion to be enhanced by 5 orders of magnitude at $513 \mathrm{~K}$ in $\mathrm{Al}$ to $\mathrm{Zn}$ welds, and this was attributed to the high strain induced vacancy concentration during USW. Notwithstanding the effect of an increased vacancy concentration, the dynamic generation of dislocations and the finer grain and substructures seen at the weld interface in USW might also be expected to enhance diffusion and potentially accelerate the rate of IMC formation. Such effects are likely to have most influence in the early stages of welding because the time for nucleation of the first IMC islands is dominated by inter-diffusion across the metal-metal weld-interface. They could also potentially accelerate spreading of the IMC islands, which is controlled by interfacial diffusion between the IMC layer and matrix [24,37]. However, once the reaction layer becomes continuous, the growth rate will become controlled by diffusion through the hard, non-deforming, IMC layer and this would not be expected to be influenced by any additional vacancies, or deformation induced substructure, in the adjoining $\mathrm{Al}$ or $\mathrm{Mg}$ matrix.

The use of a simple parabolic growth law to predict the reaction layer thickness implicitly assumes that intermetallic island impingement occurs almost instantaneously, and that the contribution of island growth to the overall intermetallic layer thickness is negligible. In Fig. $6 \mathrm{a}$ it is apparent that impingement occurred for short weld times of less than $0.25 \mathrm{sec}$ at which point the maximum thickness of the reaction layer was $\sim<\mu \mathrm{m}$; whereas the parabolic growth law still under-predicted the final layer thickens in welds of one second duration, which had an IMC layer thickness of $\sim 20 \mu \mathrm{m}$, by greater than a factor of three. Even allowing for a $10 \%$ error in the interface temperature measurements, the growth rate in USW was over double that predicted with statically obtained fitting parameters. While the more rapid island growth stage makes a significant contribution to the layer thickness [37], overall comparison with the parabolic growth model still strongly suggests that the one dimensional growth rate of the continuous IMC layer was more rapid under high strain rate dynamic than static conditions. Departure from a parabolic growth rate by continuous inter-metallic reaction layers is known to occur in situations where grain boundary diffusion dominates, and grain growth occurs within the layer, or if the layer becomes damaged by micro-cracking [38,39]. Although an increase in crystallite size in the IMC layers was observed with welding time, this was a relatively modest effect and would lead to a lower growth exponent. A more likely explanation for the enhanced growth rate is, therefore, that damage is generated in the very weak brittle intermetallic layer from the high power input dissipated in the interface region during the USW process, and this accelerates the growth rate. For example, short circuit diffusion due to micro-cracking has been observed to increase IMC growth rates in hot dip aluminising and in extreme cases results in linear growth kinetics $[39,40]$. In the SEM observations here, micro-cracking was observed in the intermetallic layer and can be seen in 
Fig. 6 b \& c, where grains have fallen out of the reaction layer during sample preparation. However, it is difficult to tell if this was a real phenomenon or a result of a combination of thermal stresses and damage induced by sample preparation.

\section{Eutectic Melting}

With high welding energies, at welding times longer than optimum, evidence of melting was seen within the IMC layer. Melting appeared to initiate at the interface between the $\mathrm{Al}_{12} \mathrm{Mg}_{17}$ sub-layer and the $\mathrm{Mg}$ substrate, but with higher welding energies indications of local melting were also observed at the interface between the $\mathrm{Al}_{12} \mathrm{Mg}_{17}$ and $\mathrm{Al}_{12} \mathrm{Mg}_{17}$ sub-layers (Fig. 6 d-e). A second eutectic reaction between $\beta$ and $\gamma$ occurs in the Al-Mg system at the slightly higher temperature of $450{ }^{\circ} \mathrm{C}$ [14], and this may account for the observation of melting at the $\beta / \gamma$ interface (Fig. 6d). The interface temperature (Fig. 5) when melting first occurred was measured to be $422{ }^{\circ} \mathrm{C}$ which, is substantially below that of the known lowest melting point $(\mathrm{Mg})_{\mathrm{SS}}+\gamma-\mathrm{Mg}_{17} \mathrm{Al}_{12} \rightarrow \mathrm{L}$ eutectic reaction in the Al-Mg binary system, of $437{ }^{\circ} \mathrm{C}$. Furthermore, near complete melting of the $\mathrm{Al}_{12} \mathrm{Mg}_{17}$ layer was seen at an interface temperature of $432^{\circ} \mathrm{C}$ (Fig. 6e).

Gundaz et al. [25] have previously suggested that the high strain rate [25] dynamic deformation that takes place during USW can also significantly reduce the melting point at the interface in metallic couples, due to the high rate of vacancy generation [25]. On the other hand, more recent modelling of the excess vacancy concentration in USW by Chen et al. [23], indicates that it is likely that the annihilation rate, in $\mathrm{Al}$, becomes comparable to the rate of generation close to the melting point, so that this effect may not be as large as previously assumed. Earlier work by Mecking and Estrin [41] also comes to the same conclusion. However, these predictions are critically dependent on the vacancy sink density, which is poorly known, and the low eutectic melting point in the Al-Mg system is in the range where an excess vacancy population is still possible [23].

In the investigation here temperatures were recorded at the hottest point in the weld interface in many repeated welds. Only the highest peak temperatures measured for a given weld energy, averaged over data consistently re-produced to $\pm 2{ }^{\circ} \mathrm{C}$ in at least three welds, have been reported (black squares in Fig. 5). Nevertheless, thermocouple measurements performed during welding experiments with a rapid thermal cycle are subject to error because of thermal lag effects and the difficulty of maintaining intimate contact and accurate thermocouple positioning. There is thus a tendency to under-record peak temperatures. From the thermocouple measurements alone, this would make it difficult to come to firm conclusions, concerning the depression of the melting point effect in USW proposed by Gundaz et al. [25]. However, DSC analysis of pre-welded samples (Fig. 14b) indicated an incipient melting reaction under static conditions at a similar temperature to that recorded in the weld thermocouple measurements of $432{ }^{\circ} \mathrm{C}$. This is only slightly below that seen in the binary eutectic system $\left(437^{\circ} \mathrm{C}\right)$. Finally, Calphad modelling indicated that, with the alloys welded, depression of the eutectic melting point relative to that reported for the binary Al-Mg system can be easily explained purely in terms of the alloy chemistry. Taken overall, it thus appears that in the current study there is no convincing evidence that the dynamic deformation during USW significantly reduced the eutectic melting point in the alloy combination investigated. This is because the concentration of vacancies required to significantly lower the melting point is extremely high (>0.01) [25] and the annihilation rate of excess vacancies close to the melting point is too large to allow a sufficient excess concentration to develop, to affect the thermodynamic stability of the solid phase by more than that due to alloying.

\section{Conclusions}


It has been shown that by high power ultrasonic spot welding sound welds can be achieved between $\mathrm{Al}$ to $\mathrm{Mg} 1 \mathrm{~mm}$ gauge sheet, with lap shear strengths equivalent to those found in optimised, similar, $\mathrm{Mg}-\mathrm{Mg}$ welds in short welding times of $\sim 0.4$ seconds. However, the dissimilar welds failed with half the fracture energy and always at the interface, rather than by nugget pull-out. This poor fracture behaviour can be related to the rapid development of a thick IMC layer at the joint interface. The thick IMC layer arises due to the high interface temperatures reached, when using sufficient power to weld sheets of this thickness, and because of the inherently fast inter-diffusion rates, and diffusion rates through the IMC reaction layer formed in the Al-Mg system. However, the IMC layer growth rate in USW was also found to be over double that found under static conditions.

For the optimum welding time the IMC reaction layer was already $5 \mu \mathrm{m}$ thick and grew to over $20 \mu \mathrm{m}$ within 1 second. The layer was comprised of two phases, $\gamma-\mathrm{Al}_{12} \mathrm{Mg}_{17}$ and $\beta$ $\mathrm{Al}_{3} \mathrm{Mg}_{2}$, which formed continuous sub-layers on the $\mathrm{Mg}$ and $\mathrm{Al}$ sides of the weld. The $\mathrm{Al}_{12} \mathrm{Mg}_{17}$ phase formed first early in the USW process, in microwelded regions that develop at contacting asperities across the sheet surfaces, as isolated islands that nucleated after sufficient inter-diffusion occurred across the interface. The $\gamma-\mathrm{Al}_{12} \mathrm{Mg}_{17}$ islands rapidly spread and coalesced to form a continuous reaction layer within a welding time of only 0.25 seconds. A second $\mathrm{Al}_{3} \mathrm{Mg}_{2} \mathrm{IMC}$ layer then developed on the $\mathrm{Al}$ side of the interface. This layer grew faster than the $\mathrm{Al}_{12} \mathrm{Mg}_{17}$ phase and became the thickest component of the reaction layer at longer weld times.

Static growth experiments have validated the parabolic rate constants measured by Tanguep Njiokep et al. [17] and confirm that growth of the $\beta-\mathrm{Al}_{3} \mathrm{Mg}_{2}$ phase has an unually low activation energy, which may be related to its complex crystal structure. Kinetic modelling using the parabolic growth law fitted to static experimental data showed that the growth rate of the continuous IMC reaction layer is over double that expected under static conditions. This difference has been attributed, partly due to the more rapid initial island growth stage, but also to the USW process increasing the growth rate by enhanced diffusion from microcracking in the brittle reaction layer. In comparison, the generation of large excess vacancy concentrations in USW by the high strain rate dynamic deformation is thought to primarily influence the early nucleation stage of the reaction, where the layer is discontinuous and interfacial diffusion dominates.

At excessive welding times ( $>1$ second), melting was observed within the IMC reaction layer. This occurred first on the $\mathrm{Mg}$ side of the layer through the lowest temperature $(\mathrm{Mg})_{\mathrm{SS}}+$ $\mathrm{Mg}_{17} \mathrm{Al}_{12} \rightarrow \mathrm{L}$ eutectic reaction present in the $\mathrm{Al}-\mathrm{Mg}$ system. The onset of melting was observed to start slightly below the eutectic reaction temperature in the binary system. This depressed melting point was confirmed by DSC analysis and can be attributed to the presence of additional elements such as $\mathrm{Cu}$ and $\mathrm{Si}$ in the AA6111 alloy.

\section{Acknowledgements}

This work was funded by the EPSRC through LATEST2, Light Alloys Towards Environmentally Sustainable Transport (EP/G022402/1) and Friction Joining - Low Energy Manufacturing for Hybrid Structures in Fuel Efficient Transport Applications (EP/G022402/1.JLR). The authors would like to thank Novelis UK and Magnesium Elektron for the provision of materials.

\section{References}


[1] I.N. Fridlyander, V.G. Sister, O.E. Grushko, V.V. Berstenev, L.M. Shevelova, L.A. Ivanova, Met. Sci. Heat Treat. 44 (2002) 365-370

[2] D. Carle, G. Blount, Mater. Des. 20 (1999) 267-272

[3] A. Jambor, M. Beyer, Mater. Des. 18 (1997) 203-209

[4] X. Cui, S. Wang, S.J. Hu, Mater. Des. 29 (2008) 381-387

[5] P. Venkateswaran, Z.-H. Xu, X. Li, A.P. Reynolds, J. Mater. Sci. 44 (2009) 4140-4147

[6] Y. Du, Y.A. Chang, B. Huang, W. Gong, Z. Jin, H. Xu, Z. Yuan, Y. Liu, Y. He, F.-Y. Xie, Mater. Sci. Eng. A 363 (2003) 140-151

[7] V. Firouzdor, S. Kou, Metall. Mater. Trans. A, 41A (2010) 2914-2935

[8] D.-H. Choi, B.-W. Ahn, C.-Y. Lee, Y.-M. Yeon, K. Song, S.-B. Jung, Intermet. 19 (2011) $125-130$

[9] J. Yan, Z. Xu, Z. Li, L. Li, S. Yang, Scripta Mater. 53 (2005) 585-589

[10] Y.J. Kwon, I. Shigematsu, N. Saito, Mater. Lett. 62 (2008) 3827-3829

[11] A. Kostka, R.S. Coelho, J. dos Santos, A.R. Pyzalla, Scripta Marter. 60(2009) 953-956

[12] Y.S. Sato, S.H.C. Park, M. Michiuchi, H. Kokawa, Scripta Mater. 50 (2004) 1233-1236

[13] H.L. Su, M. Harmelin, P. Donnadieu, C. Baetzner, H.J. Seifert, H.L. Lukas, G. Effenberg, F. Aldinger, J. Alloy. Compd. 247 (1997) 57-65

[14] J.L. Murray. In: T.B. Massalski (ed.) Binary Alloy Phase Diagrams, $2^{\text {nd }}$ ed., Metals Park OH ASM Int. 1 (1990) 169-171

[15] A.C. Somasekharan, L.E. Murr, Mater.Charact. 52 (2004) 49-64

[16] Z.F. Li, J. Dong, X.Q. Zeng, C. Lu, W.J. Ding, Z.M Ren, J Alloy. Compd. 440 (2007) 132-136 I

[17] E.M. Tanguep Njiokep, M. Salamon, H. Mehrer, Defect Diffus. Forum Vols. 194-199 (2001) 1581-1586

[18] D. Dietrich, D. Nickel, M. Krause, T. Lampke, M.P. Coleman, V. Randle, J. Mater. Sci. 46 (2011) 357-364

[19] V. Rothova, J. Cermak, Interdiffusion in $\mathrm{Mg} / \mathrm{Mg}_{17} \mathrm{Al}_{12}$ System, Metal 2006: 15th Int. Metallurgical \& Material Conference, Czech Republic 2006

[20] R. Jahn, R. Cooper, D. Wilkosz, Metall. Mater. Trans. A, 38A (2007) 570-583

[21] H.C.P. Daniels, Ultrasonics, (1965) 190-196

[22] D. Bakavos, P.B. Prangnell, Mer. Sci. Eng. A 527 (2010) 6320-6334

[23] Y.-C. Chen, D. Bakavos, P.B. Prangnell, Acta Mater. 60 (2012) 2816-2828

[24] J.L. Harthoorn, Doctoral Thesis, De Technische Hogeschool Eindhoven, 1978

[25] I.E. Gundaz, T. Ando, E. Shattuck, P.Y. Wong, C.C. Doumanidis, Scripta Mater. 52 (2005) 939-943

[26] A. Panteli, Y.-C. Chen, D. Strong, X. Zhang, P.B. Prangnell, JOM, 64:3 (2012) 414-420

[27] R.W. Balluffi, S.M. Allen, W.C. Carter, R.A. Kemper, Kinetics of Materials, John Wiley and Sons, 2005.

[28] D. Bakavos, P.B. Prangnell, Y.-C. Chen. In: F. Balle, editor, Proceedings of TMS 2011, vol 1. San Diego, CA: TMS (2011) p.735

[29] F. Laves, K. Moeller, Z. Metallk. 30 (1938) 232-235

[30] S. Samson, Acta Cryst. 19 (1965) 401-413

[31] J. Timm, H.A. Warlimont, Zeitschrift fur Metallkunde 71 (1980) 434-437

[32] M. Feuerbacher, C. Thomas, J.P.A. Makongo et al., Z. Kristallogr. 222 (2007) 259-288

[33] N. Saunders, U.K.Z. Guo, X. Li, A.P. Midownik, J.-Ph. Schille, JOM 55 (2003) 60-65

[34] L. Peng, L. Yajiang, G. Haoran, W. Juan, Vac. 80 (2006) 395-399

[35] J. Philibert, Mater. Sci. Forum Vols. 155-156 (1994) 15-30

[36] S. Fujikawa, K. Hirano, Mater. Sci. Eng. 27 (1977) 25-33

[37] J. D. Robson, A. Panteli, N. Iqbal, P. B. Prangnell, Sci Technol of Welding and Joining, in press. 
[38] R. W. Richards, R. D. Jones, P. D. Clements, H. Clarke, Int. Materials Reviews 39 (1994) 191-209.

[39] H. Springer, A. Kostka, J.F. dos Santos, D. Raabe, Mater. Sci. Eng. A 528 (2011) 46304642

[40] L. Xu, Y.Y. Cui, Y.L. Hao, R. Yang, Mater. Sci. Eng. A 435-436 (2006) 638-647

[41] H. Mecking, Y. Estrin, Scripta Metall. 14 (1980) 815-819 


\section{Figure Captions}

Table 1. Kinetic growth rate constants measured by Tanguep Njiokep et al. and determined here for the entire IMC layer thickness [17].

Figure 1: The binary Al-Mg phase diagram adapted from [7] with the eutectic reaction temperatures indicated.

Figure 2: Lap shear test results, as a function of weld energy and time, showing (a) the peak failure load and (b) energy of fracture for the dissimilar Al-Mg ultrasonic welds compared to similar Al-Al and Mg-Mg welds.

Figure 3: Examples of the failure behaviour of optimised (a) $\mathrm{Al}-\mathrm{Al}$, (b) $\mathrm{Mg}-\mathrm{Mg}$ welds and (c) a low energy (300 J, $0.24 \mathrm{~s}$ ) and (d) a high energy (1000 J, $0.8 \mathrm{~s}$ ) Al-Mg weld, showing both halves of the fractured lap shear test samples.

Figure 4: Macroscopic cross sections through the weld centre lines for Al-Mg dissimilar USWs produced with (a) $600 \mathrm{~J}$ and (b) $1200 \mathrm{~J}$ welding energies.

Figure 5: Measurements of the weld peak interface temperature, as a function of welding energy, repeated many times. The maximum values highlighted as solid points were repeatable within $\pm 2^{\circ}$ and are averaged from three repeated tests.

Figure 6: SEM images of the joint interface at the weld centre showing the IMC layer development with increasing welding duration; (a) $0.24 \mathrm{~s}$, (b) $0.40 \mathrm{~s}$, (c) $0.70 \mathrm{~s}$, (d) $1.00 \mathrm{~s}$ and (e) $1.26 \mathrm{~s}$.

Figure 7: EBSD pattern quality and phase discriminated maps of weld interface regions showing the IMC layer development with increasing welding durations of; (a) 0.30, (b) 0.50, (c) 0.70 and (d) 0.90 seconds.

Figure 8: X-ray diffraction spectrum performed on (a) the $\mathrm{Mg}$ side and (b) the $\mathrm{Al}$ side of fractured weld samples for the 0.7 second weld, showing the presence of both $\mathrm{Al}_{3} \mathrm{Mg}_{2}$ and $\mathrm{Al}_{12} \mathrm{Mg}_{17}$ phases, as well as $\mathrm{Al}$ and $\mathrm{Mg}$.

Figure 9: Typical EDS line scan performed across the IMC reaction layer in the 1.0 second weld sample.

Figure 10: $\{100\}\{110\}$ and $\{111\}$ pole figures from EBSD maps of the $\mathrm{Al}_{3} \mathrm{Mg}_{2}$ layer in the 0.7 second weld sample.

Figure 11: Hardness profile across the weld interface for the 0.9 second weld sample.

Figure 12: Isothermal reaction kinetic data compared to the results of Tanguep Njiokep et al. [17], (a) $\ln$ (thickness) plotted against $\ln$ (time), at a constant temperature of $400{ }^{\circ} \mathrm{C}$, and (b) $\ln$ (thickness) plotted against inverse temperature, for a constant time of 72 hours.

Figure 13: (a) Calculation of the activation energy (Q) for the layer growth rate from static heat treatments performed at various temperatures for a constant time of 72 hours. (b) IMC thickness measurements for isothermal treatments at $380^{\circ} \mathrm{C}$ and $400^{\circ} \mathrm{C}$, including data from Tanguep Njiokep et al [17] (open points), with predictions calculated using equation 3 (solid lines). 
Figure 14: (a) Thermal histories for 5 dissimilar Al-6111 and Mg-AZ31 USWs produced with welding energies of 529, 768, 1015, 1152 and $1567 \mathrm{~J}$ and (b) the predicted corresponding IMC layer growth for each weld using the fitted parabolic growth law. In (c) a comparison is made between the predicted reaction layer thickness, using static fitting parameters, and the measured layer thickness after USW. The effect of scaling the weld thermal cycle by $5 \%$ and $10 \%$, to simulate the effect of under measuring the weld temperatures, is also shown.

Figure 15: (a) Calphad predictions of the solidification range of the AZ31-AA611 alloy couple, compared to that of the binary Al-Mg alloy, at the $(\mathrm{Mg})_{\mathrm{SS}}+\mathrm{Mg}_{17} \mathrm{Al}_{12} \rightarrow$ liquid eutectic composition, illustrating the effect of alloy additions, such as $\mathrm{Cu}$, on depressing the melting point. (b) DSC analysis of a 1 second welded sample indicating the onset of melting, under static ramp-heating conditions, with a heating rate of $10 \mathrm{~K} \mathrm{~s}^{-1}$.

\section{Table 1}

\begin{tabular}{lll} 
Source & $\mathrm{k}_{0}\left(\mu \mathrm{m}^{2} \mathrm{~s}^{-1}\right)$ & $\mathrm{Q}\left(\mathrm{kJ} \mathrm{mol}^{-1}\right)$ \\
\hline Present study (full layer) & $5 \times 10^{4}$ & 65 \\
Tanguep Njiokep et al [17] $\left(\mathrm{Al}_{3} \mathrm{Mg}_{2}\right.$ layer $)$ & $3.5 \times 10^{4}$ & $69 \pm 4$ \\
\hline
\end{tabular}




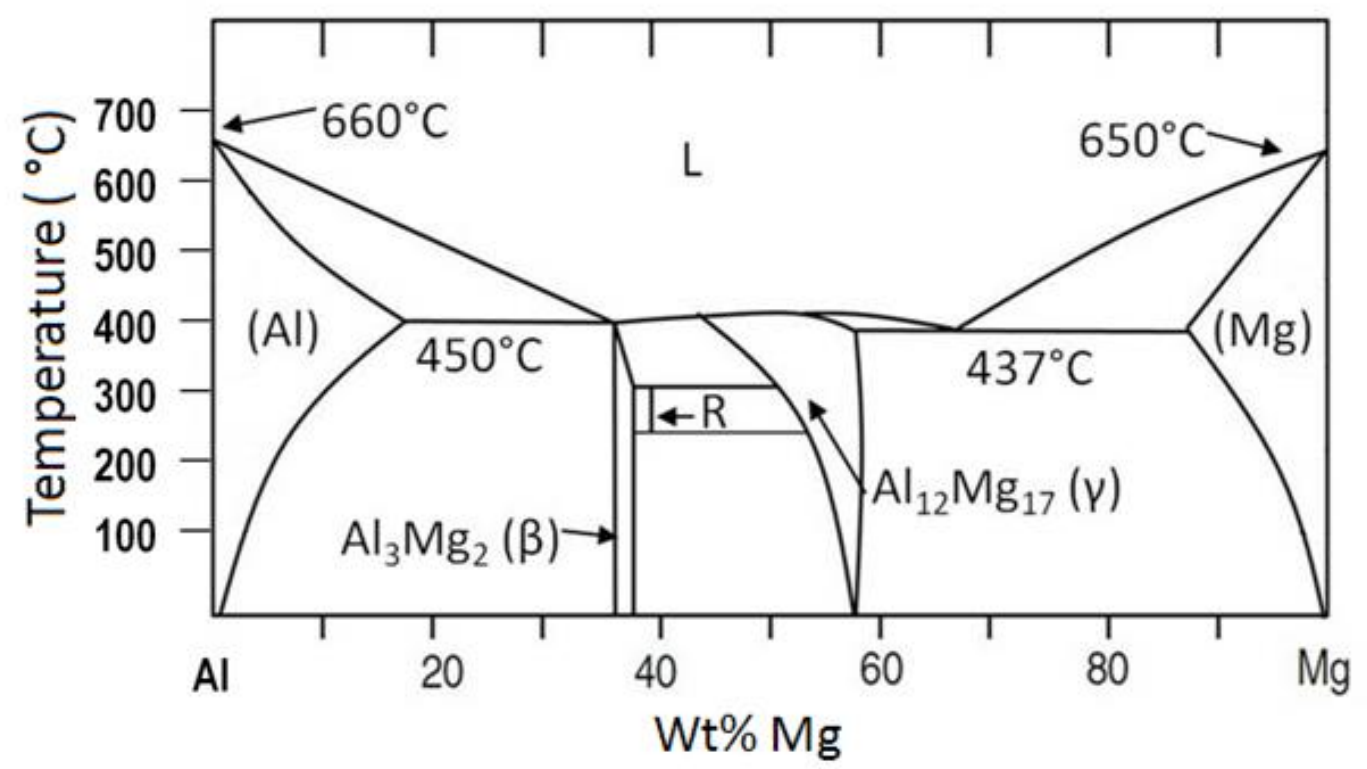

Figure 1: The binary Al-Mg phase diagram according to Firouzdor and Kou with the eutectic reaction temperatures indicated [7]. 

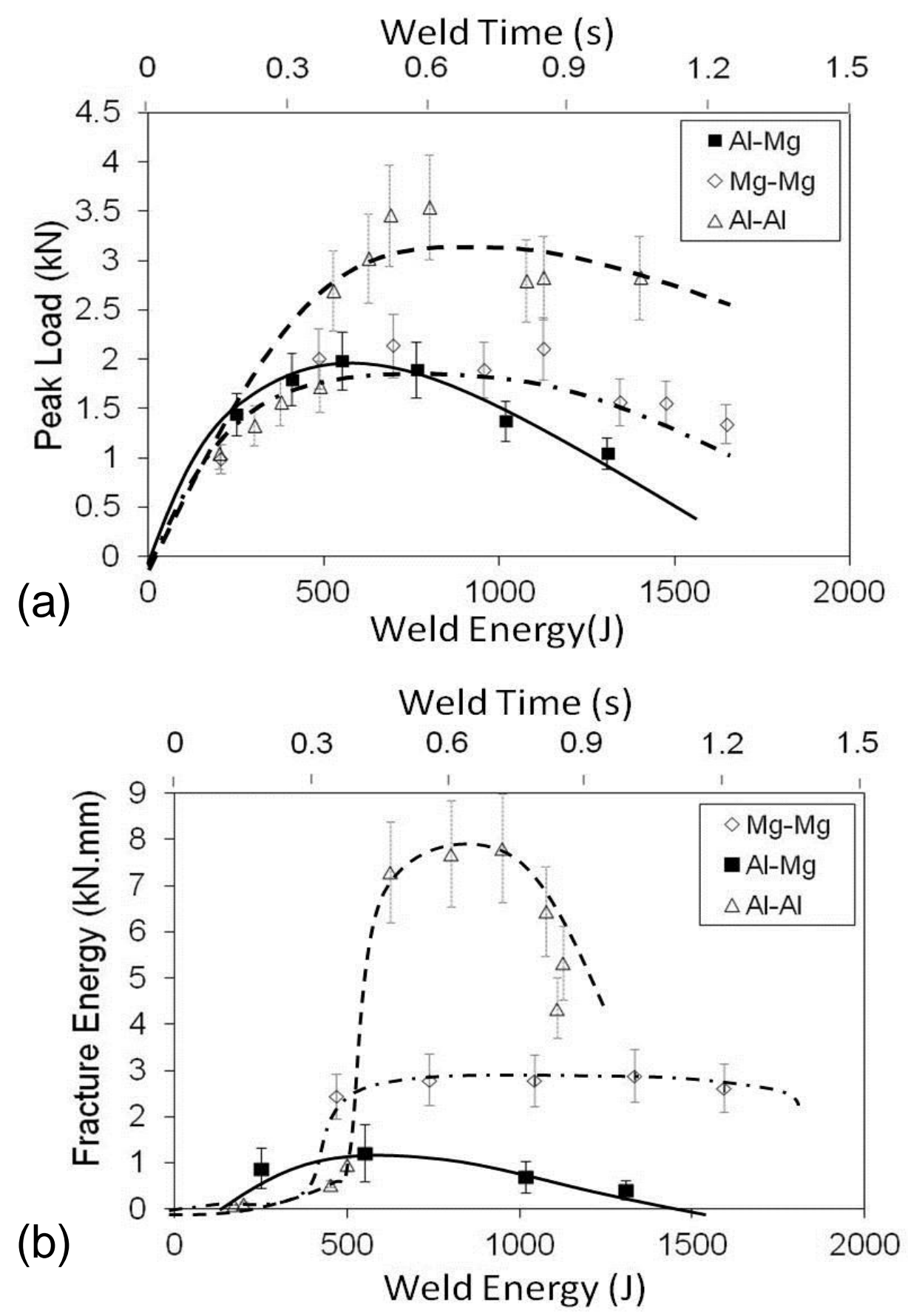

Figure 2: Lap shear test results, as a function of weld energy and time, showing (a) the failure peak load and (b) energy of fracture for dissimilar $\mathrm{Al}-\mathrm{Mg}$ welds compared to similar $\mathrm{Al}-\mathrm{Al}$ and $\mathrm{Mg}-\mathrm{Mg}$ welds. 

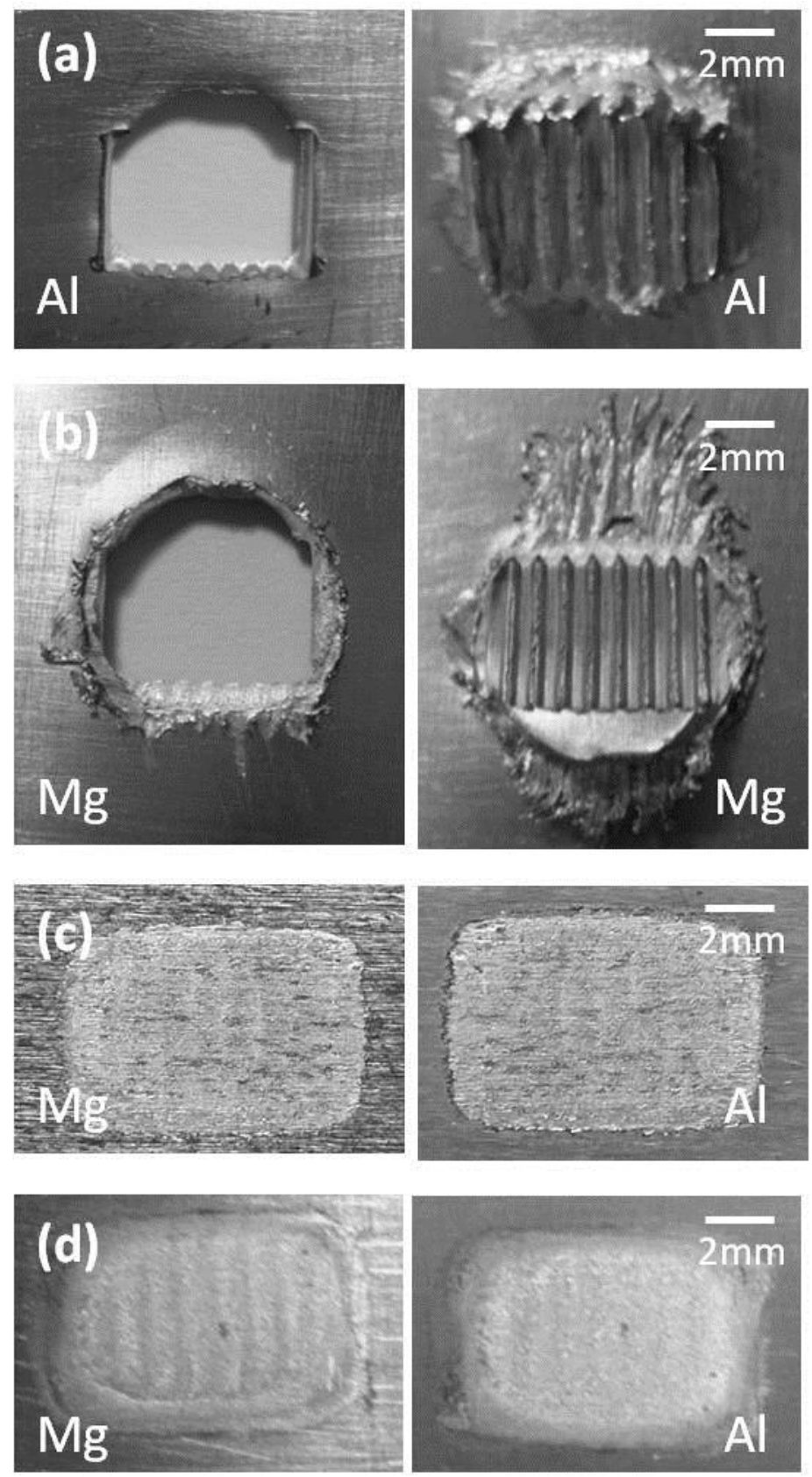

Figure 3: Examples of the failure behaviour of optimised (a) Al-Al, (b) Mg-Mg welds and (c) a low energy (300 J, $0.24 \mathrm{~s}$ ) and (d) a high energy (1000 J, $0.8 \mathrm{~s}$ ) Al-Mg weld, showing both halves of the fractured lap shear test samples. 


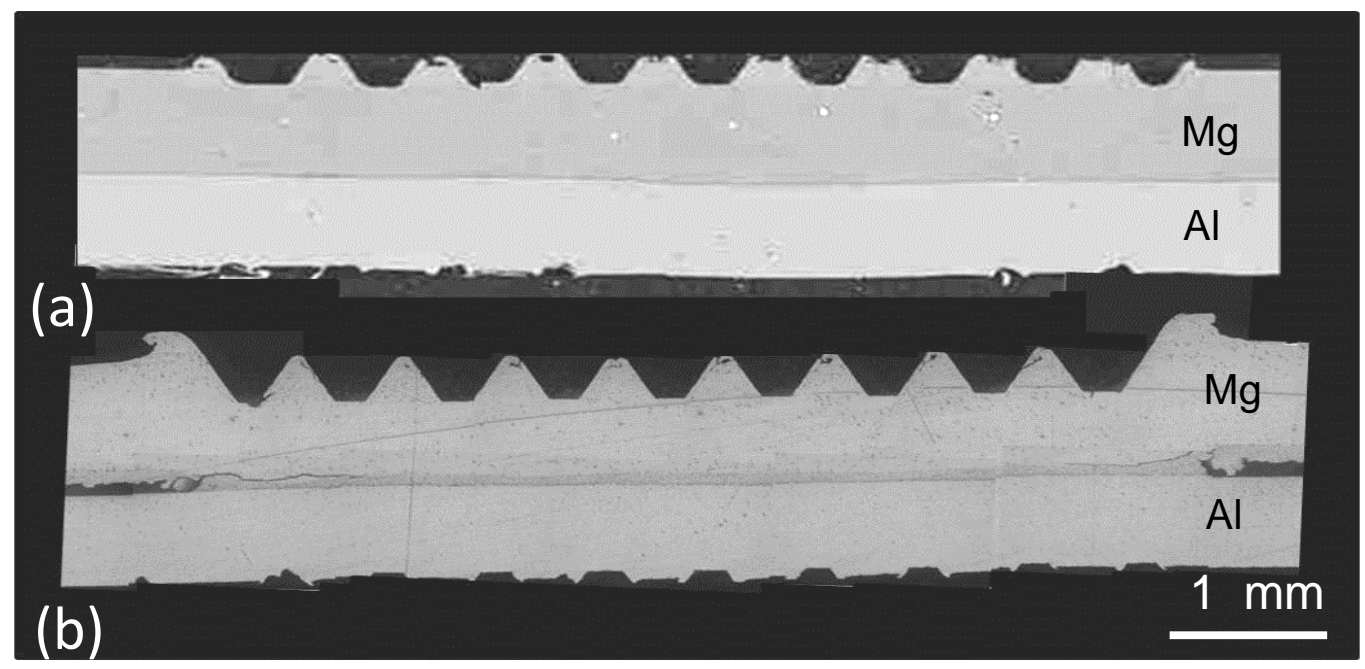

Figure 4: Macroscopic cross sections through the weld centre lines for AlMg dissimilar USWs produced with (a) $600 \mathrm{~J}$ and (b) $1200 \mathrm{~J}$ welding energies. 


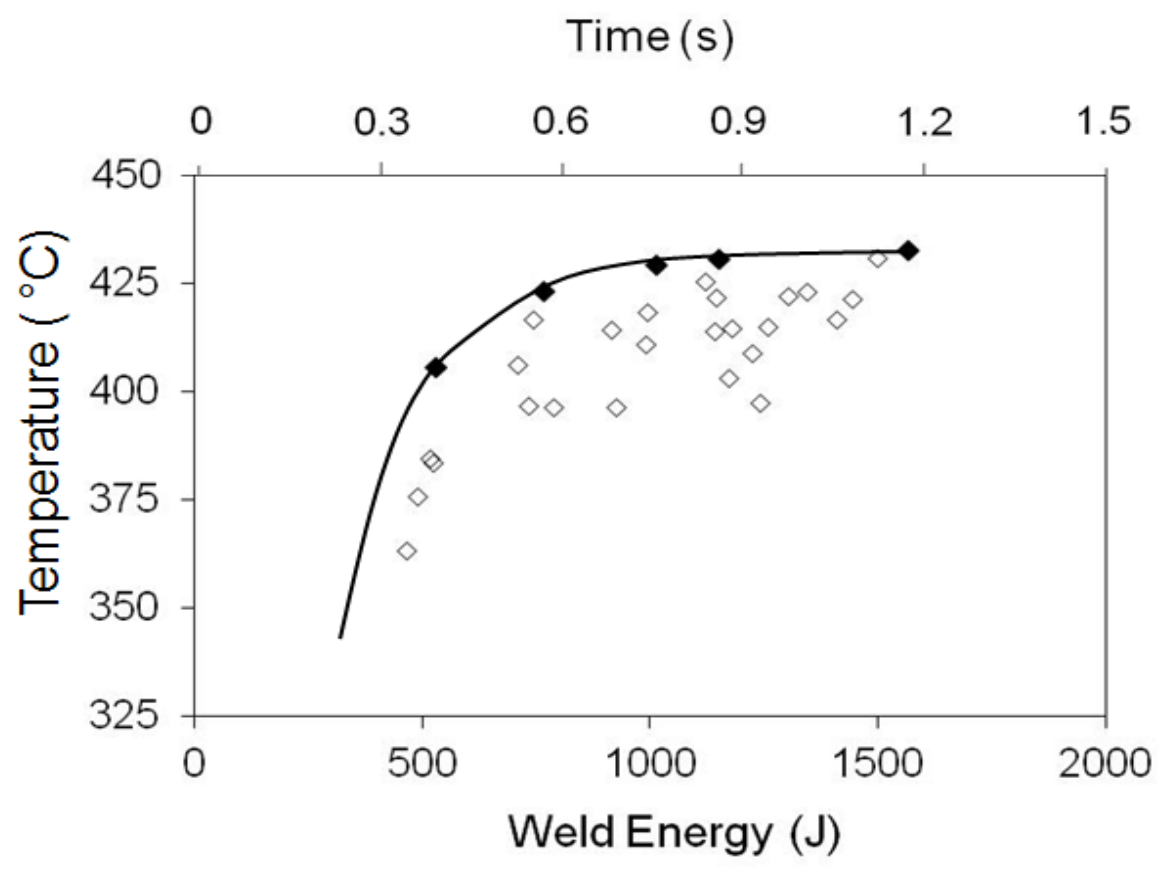

Figure 5: Measurements of the weld peak interface temperature, as a function of welding energy, repeated many times. The maximum values highlighted as solid points were repeatable within $\pm 2^{\circ}$ and are averaged from three repeated tests. 

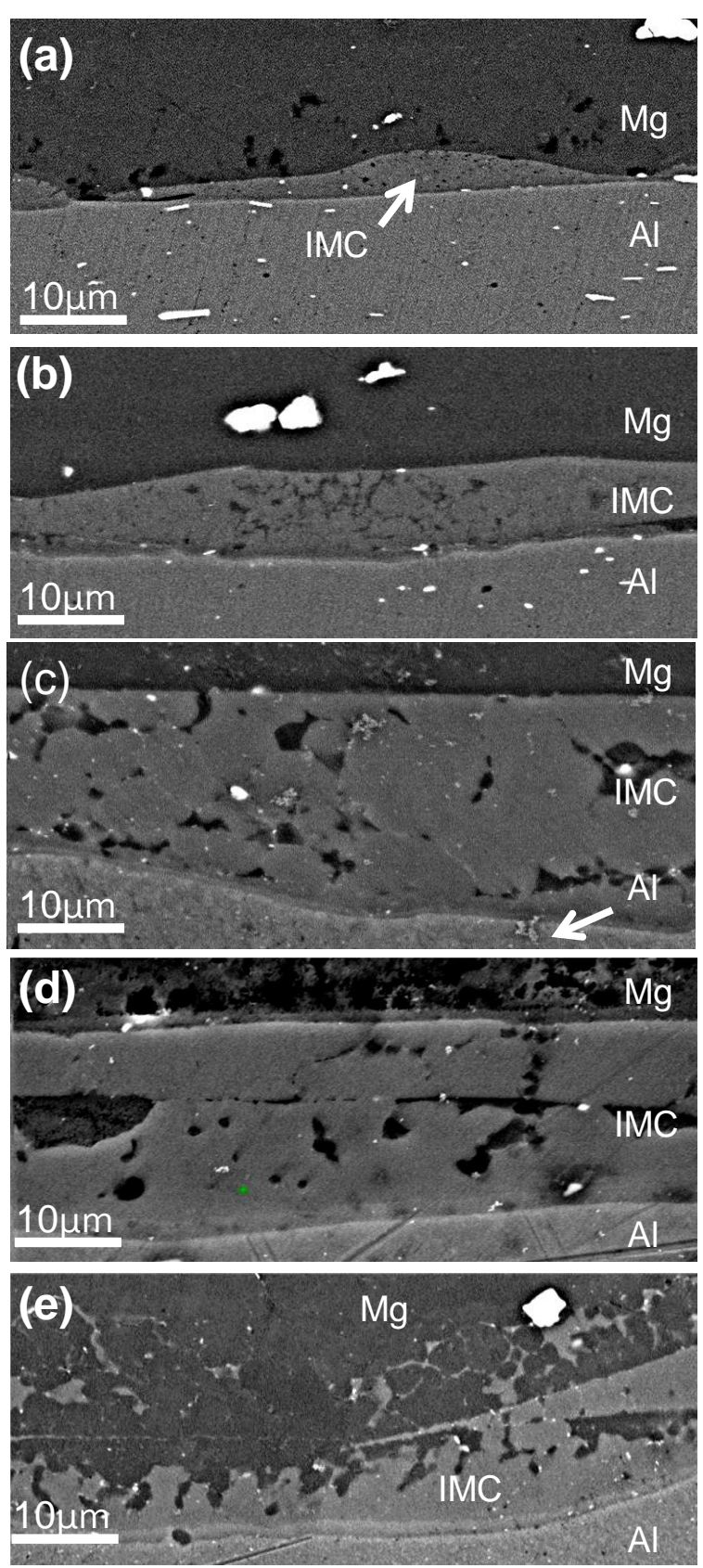

Figure 6: SEM images of the joint interface at the weld centre showing the IMC layer development with increasing welding duration; (a) 0.24 $\mathrm{s}$, (b) $0.40 \mathrm{~s}$, (c) $0.70 \mathrm{~s}$, (d) $1.00 \mathrm{~s}$ and (e) $1.26 \mathrm{~s}$. 

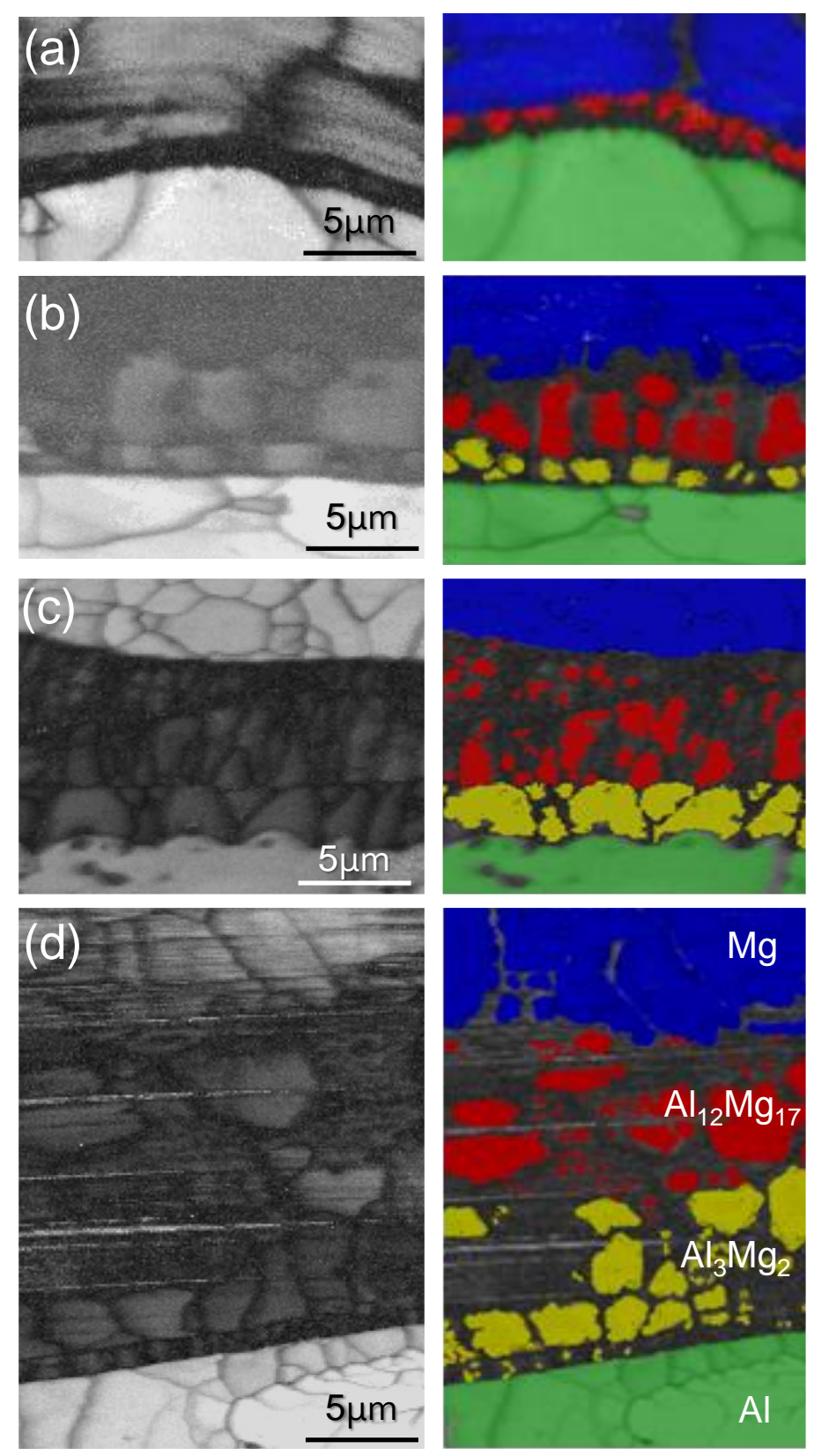

Figure 7: EBSD pattern quality and phase discriminated maps of weld interface regions showing the IMC layer development with increasing welding durations of; (a) 0.30 , (b) 0.50 , (c) 0.70 and (d) 0.90 seconds. 


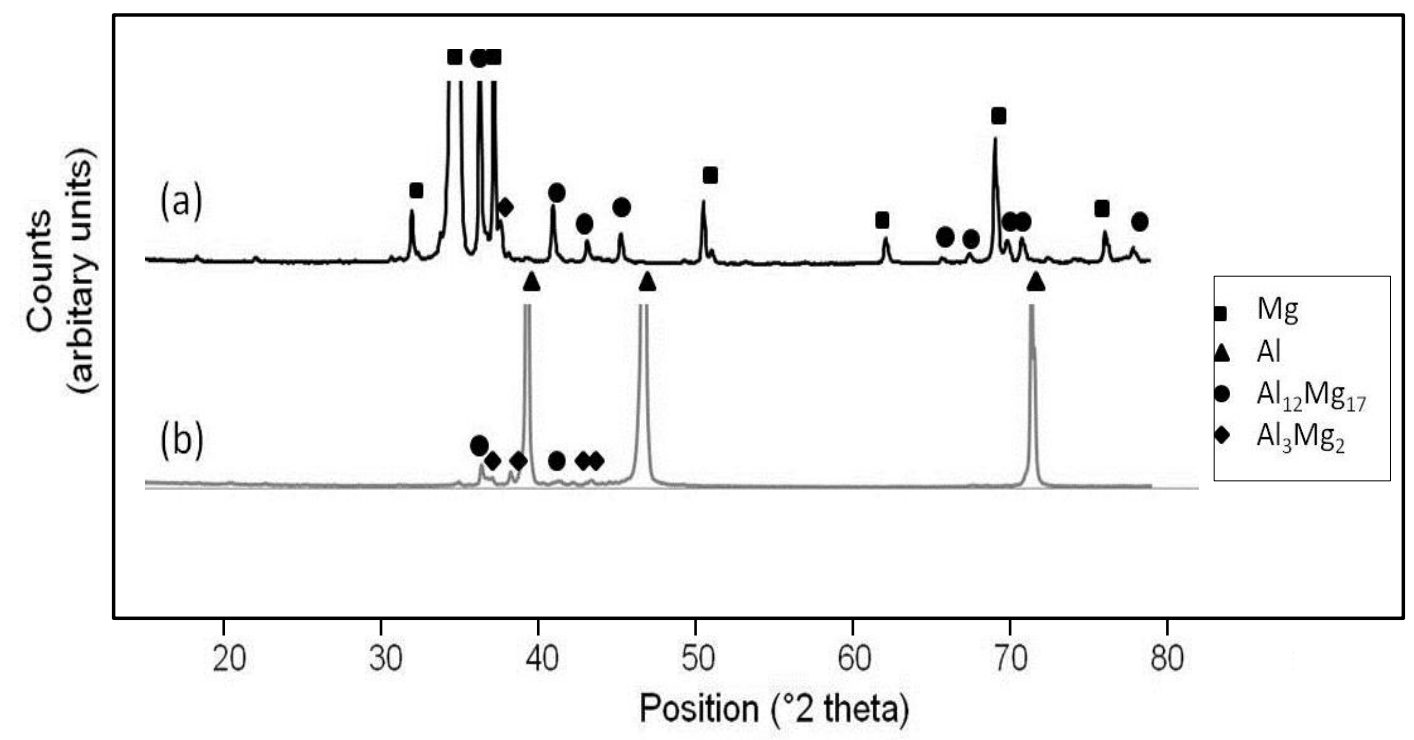

Figure 8: X-ray diffraction spectrum performed on (a) the $\mathrm{Mg}$ side and (b) the Al side of fractured weld samples for the 0.7 second weld, showing the presence of both $\mathrm{Al}_{3} \mathrm{Mg}_{2}$ and $\mathrm{Al}_{12} \mathrm{Mg}_{17}$ phases, as well as $\mathrm{Al}$ and $\mathrm{Mg}$. 


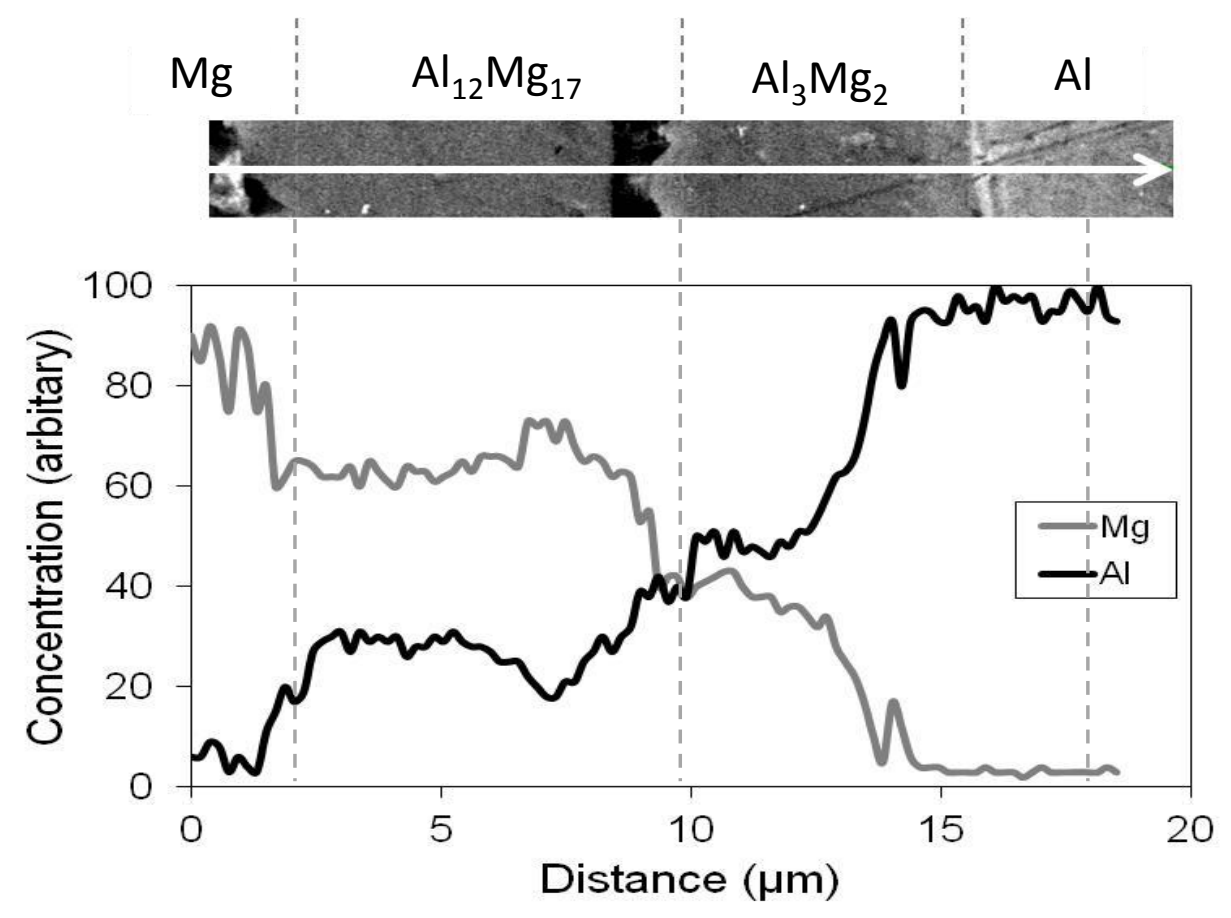

Figure 9: EDS line scan performed across the IMC reaction layer in the 1.0 second weld sample. 


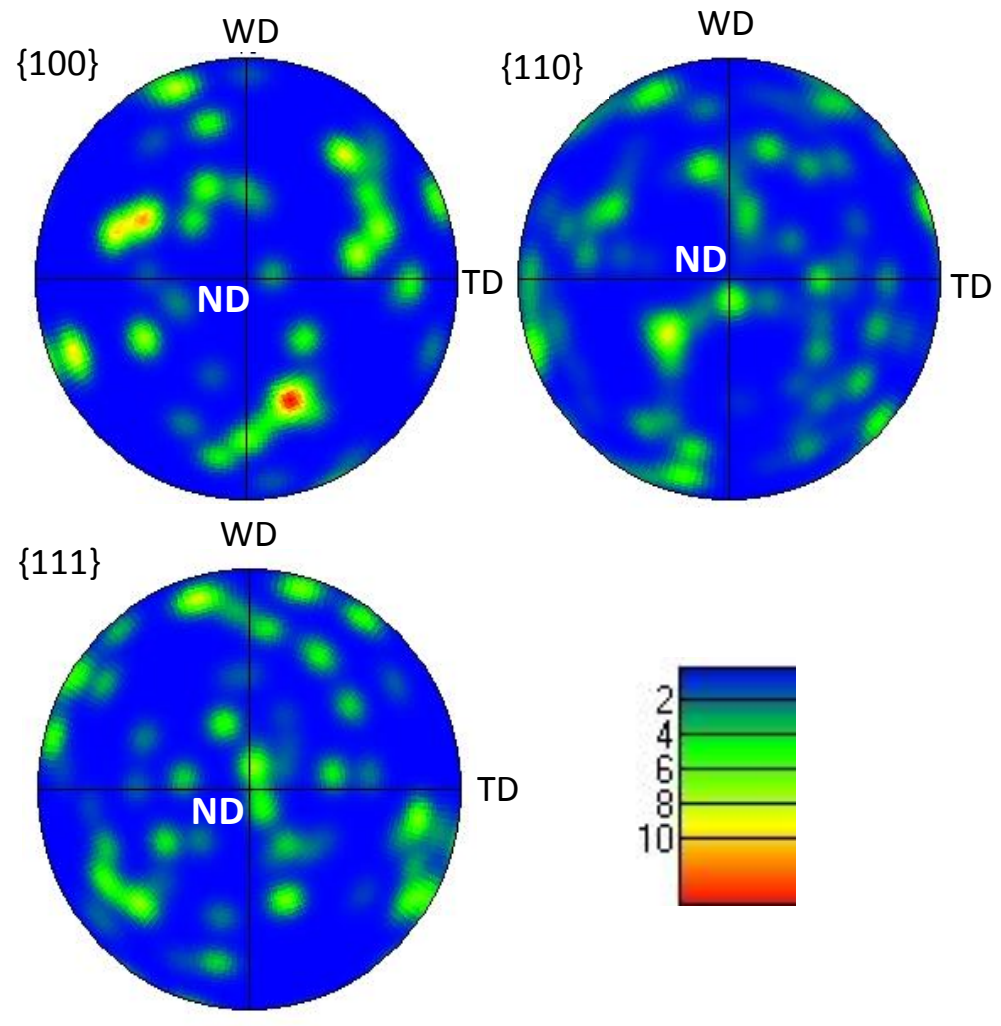

Figure 10: $\{100\}\{110\}$ and $\{111\}$ pole figures from EBSD maps of the $\mathrm{Al}_{3} \mathrm{Mg}_{2}$ layer in the 0.7 second weld sample.. 


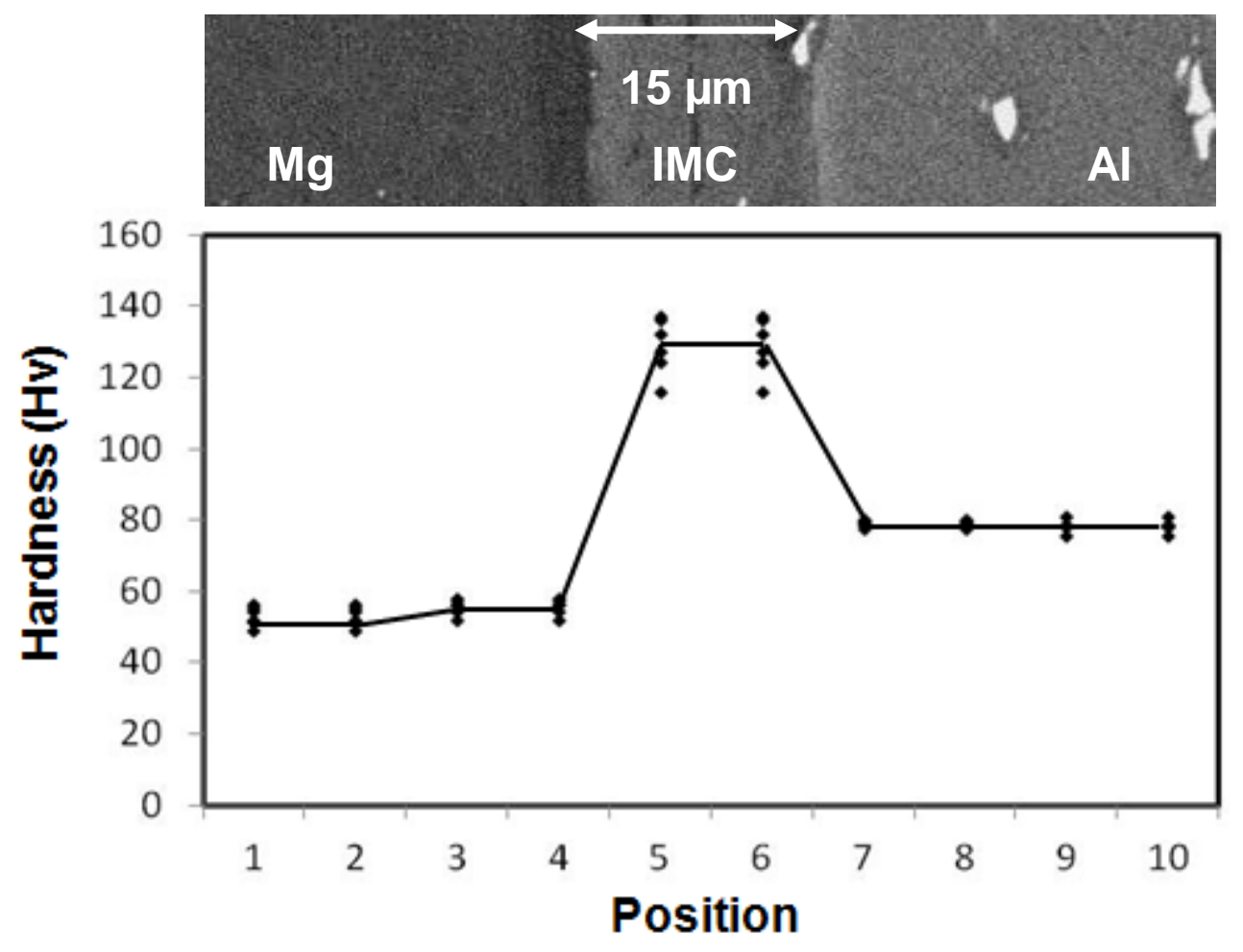

Figure 11: Hardness profile across the weld interface for the 0.9 second weld sample. 

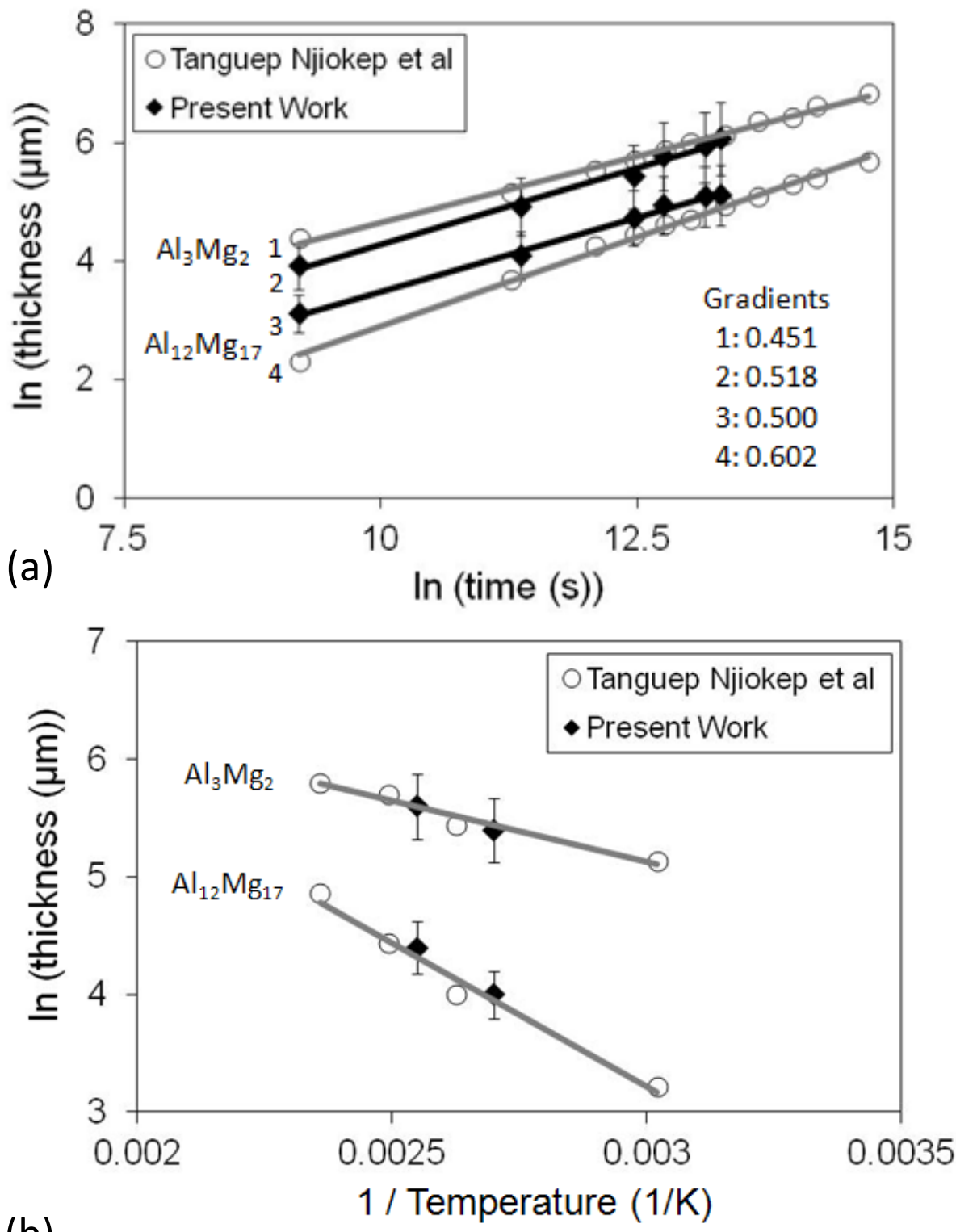

(b)

Figure 12: Isothermal reaction kinetic data compared to the results of Tanguep Njiokep et al. [17], (a) In(thickness) plotted against In(time), at a constant temperature of $400{ }^{\circ} \mathrm{C}$, and (b) In(thickness) plotted against inverse temperature, for a constant time of 72 hours. 


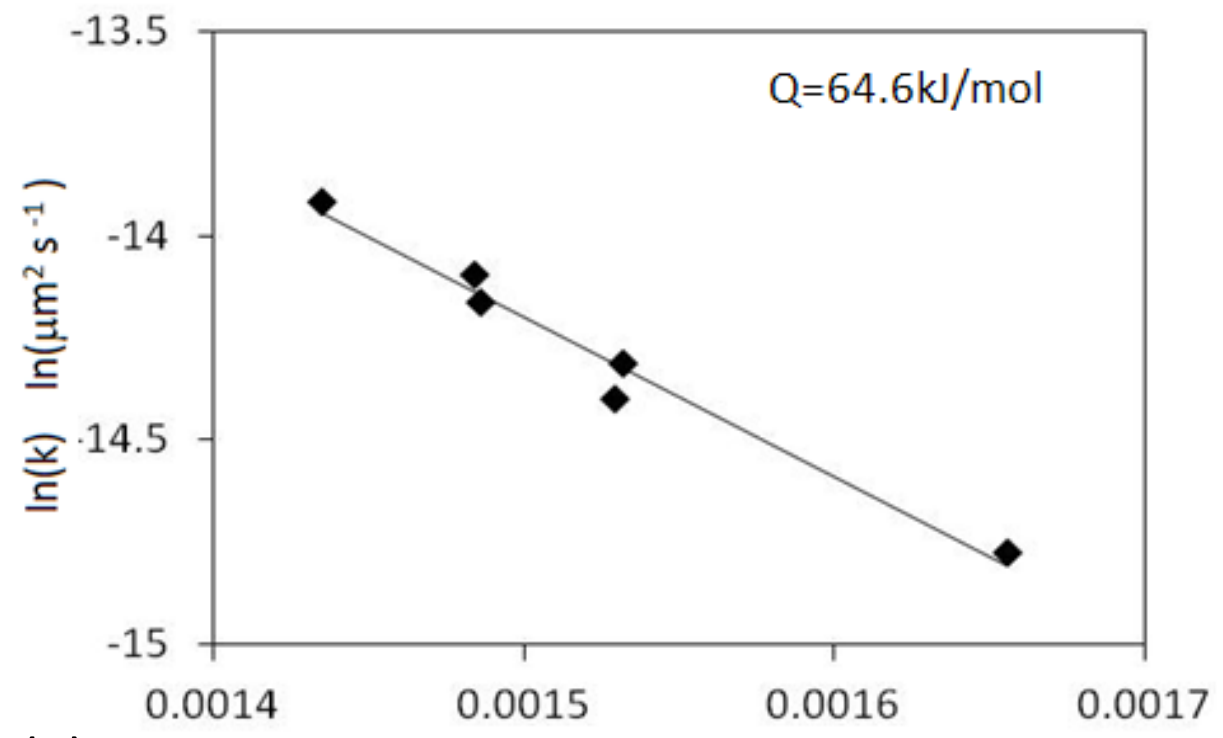

(a)

$1 /$ Temperature $(1 / \mathrm{K})$

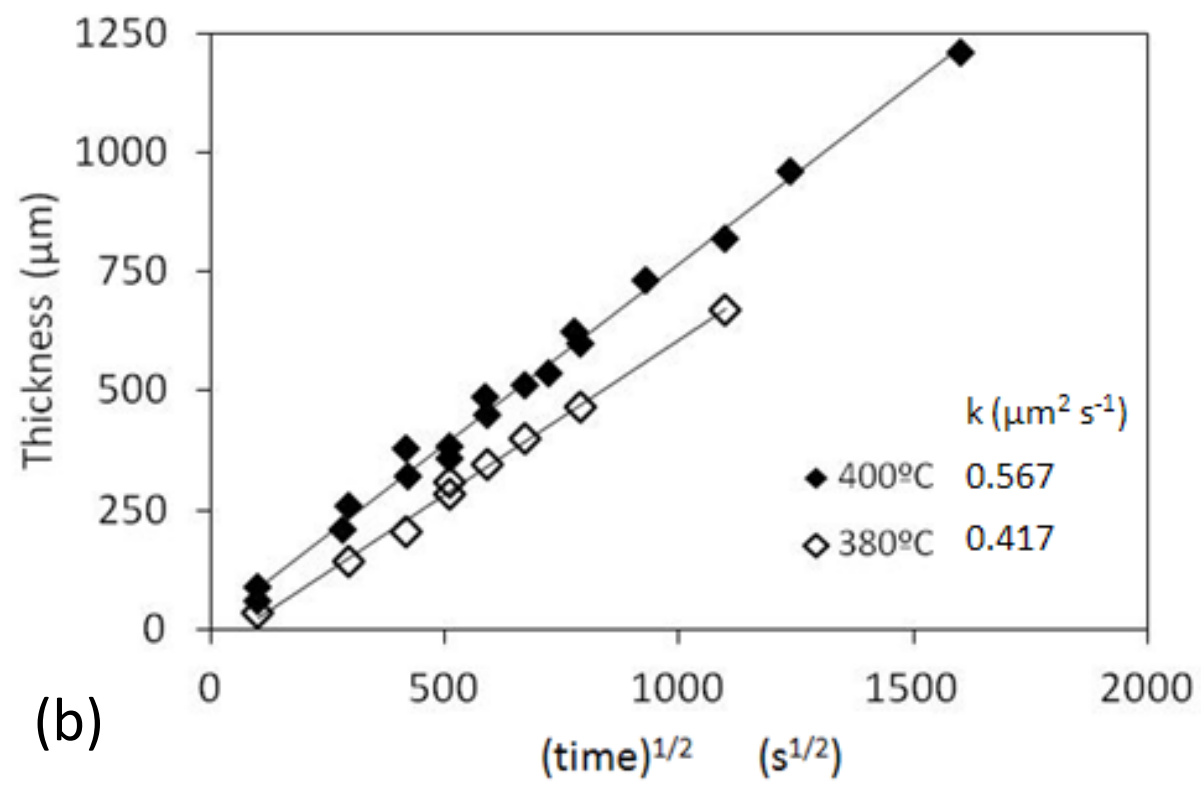

Figure 13: (a) Calculation of the activation energy $(Q)$ for the layer growth rate from static heat treatments performed at various temperatures for a constant time of 72 hours. (b) IMC thickness measurements for isothermal treatments at $380^{\circ} \mathrm{C}$ and $400^{\circ} \mathrm{C}$, including data from Tanguep Njiokep et al [17] (open points), with predictions calculated using equation 3 (solid lines). 

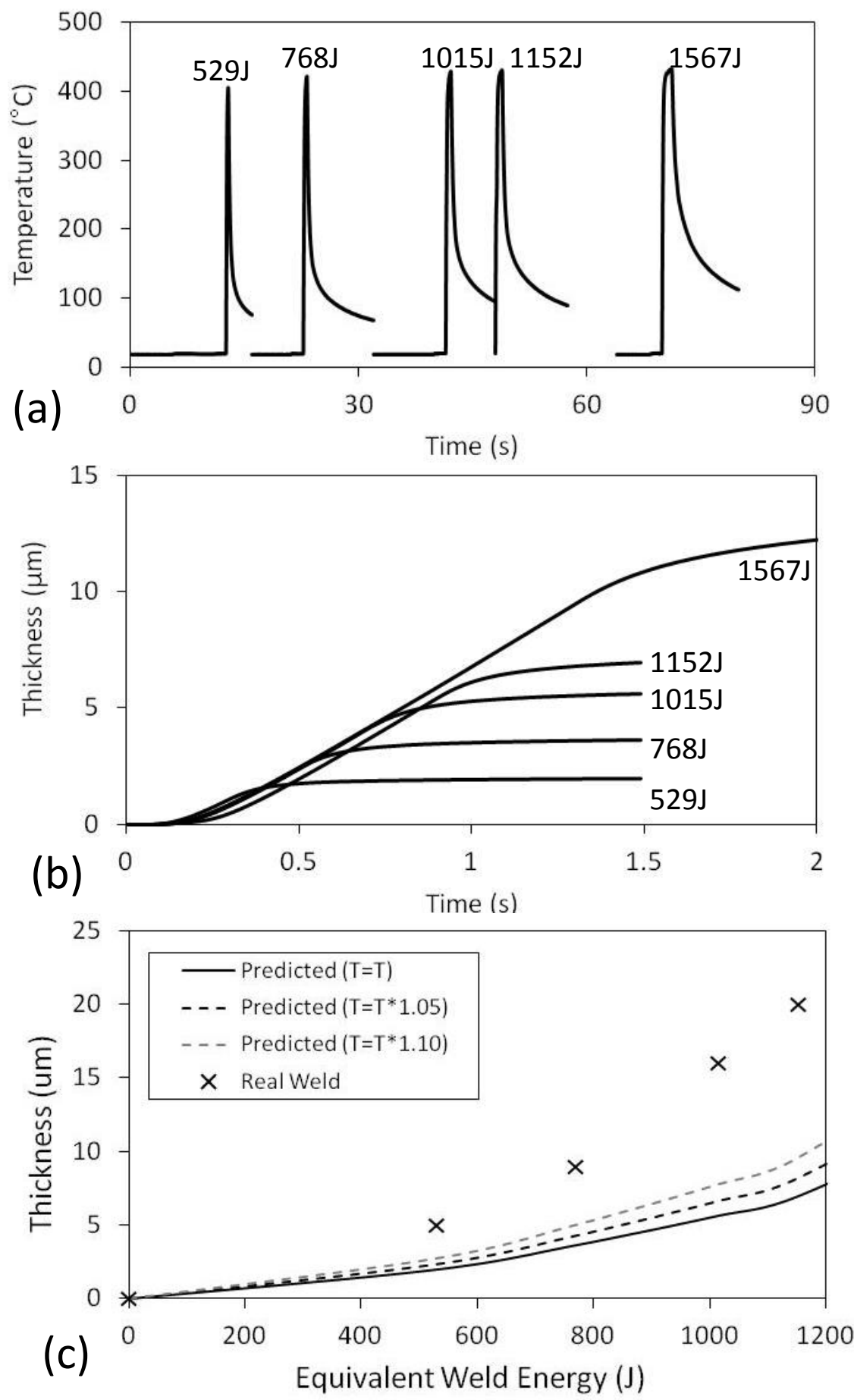

Figure 14: (a) Thermal histories for 5 dissimilar Al-6111 and Mg-AZ31 USWs produced with welding energies of $529,768,1015,1152$ and $1567 \mathrm{~J}$ and (b) the predicted corresponding IMC layer growth for each weld using the fitted parabolic growth law. In (c) a comparison is made between the predicted reaction layer thickness, using static fitting parameters, and the measured layer thickness after USW. The effect of scaling the weld thermal cycle by $5 \%$ and $10 \%$, to simulate the effect of under measuring the weld temperatures, is also shown. 

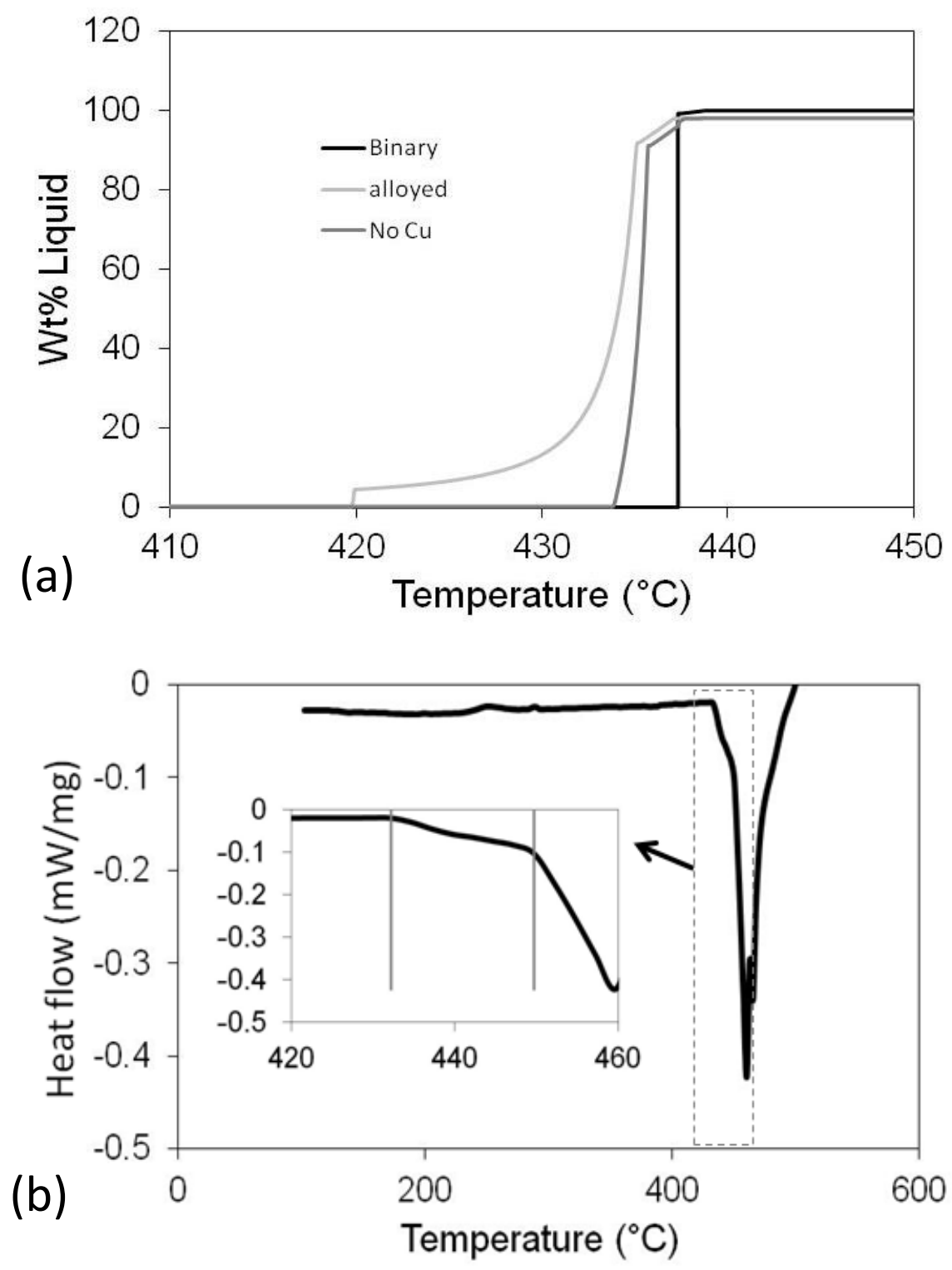

Figure 15: (a) Calphad predictions of the solidification range of the AZ31-AA611 alloy couple, compared to that of the binary Al-Mg alloy, at the $(\mathrm{Mg})_{\mathrm{Ss}}+\mathrm{Mg}_{17} \mathrm{Al}_{12} \rightarrow$ liquid eutectic composition, illustrating the effect of alloy additions, such as $\mathrm{Cu}$, on depressing the melting point. (b) DSC analysis of a 1 second welded sample indicating the onset of melting, under static ramp-heating conditions, with a heating rate of $10 \mathrm{~K} \mathrm{~s}^{-1}$. 